\title{
Design, Synthesis, and Antitumor Evaluation of Novel Histone Deacetylase Inhibitors Equipped with a Phenylsulfonylfuroxan Module as a Nitric Oxide Donor
}

\author{
Wenwen Duan ${ }^{\dagger}$, Jin $\mathrm{Li}^{\dagger}$, Elizabeth S. Inks ${ }^{\ddagger}$, C. James Chou ${ }^{\ddagger}$, Yuping Jia§, Xiaojing Chu", \\ Xiaoyang $\mathrm{Li}^{\dagger}$, Wenfang $\mathrm{Xu}^{*},{ }^{\dagger}$, and Yingjie Zhang ${ }^{*}, \dagger$ \\ tDepartment of Medicinal Chemistry, School of Pharmacy, Shandong University, Ji'nan, \\ Shandong 250012, People's Republic of China \\ FDepartment of Drug Discovery and Biomedical Sciences, South Carolina College of Pharmacy, \\ Medical University of South Carolina, Charleston, South Carolina 29425, United States \\ §Shandong Academy of Pharmaceutical Sciences, Ji'nan, Shandong 250101, People's Republic \\ of China \\ "Weifang Bochuang International Biological Medicinal Institute, Weifang, Shandong 261061, \\ People's Republic of China
}

\section{Abstract \\ On the basis of the strategy of creating multifunctional drugs, a novel series of phenylsulfonylfuroxan-based hydroxamates with histone deacetylase (HDAC) inhibitory and nitric oxide (NO) donating activities were designed, synthesized, and evaluated. The most potent NO donor-HDAC inhibitor (HDACI) hybrid, 5c, exhibited a much greater in vitro antiproliferative activity against the human erythroleukemia (HEL) cell line than that of the approved drug SAHA (Vorinostat), and its antiproliferative activity was diminished by the NO scavenger hemoglobin in a dose-dependent manner. Further mechanism studies revealed that $\mathbf{5 c}$ strongly induced cellular apoptosis and G1 phase arrest in HEL cells. Animal experiment identified $\mathbf{5 c}$ as an orally active agent with potent antitumor activity in a HEL cell xenograft model. Interestingly, although compound $\mathbf{5 c}$ was remarkably HDAC6-selective at the molecular level, it exhibited pan-HDAC inhibition in a western blot assay, which is likely due to class I HDACs inhibition caused by NO release at the cellular level.}

\author{
Abstract \\ *Corresponding Authors: (W.X.) Phone: 86-531-88382264. Fax: 86-531-88382264. wenfxu@ gmail.com. (Y.Z.) Phone: \\ 86-531-88382009. Fax: 86-531-88382009. zhangyingjie@ sdu.edu.cn. \\ ASSOCIATED CONTENT \\ Supporting Information \\ ${ }^{1} \mathrm{H}$ and ${ }^{13} \mathrm{C}$ NMR spectra of all targets compounds and HPLC analysis chromatograms of representative target compounds $\mathbf{5 a}, \mathbf{5 b}, \mathbf{5 c}$, \\ and 5j. The Supporting Information is available free of charge on the ACS Publications website at DOI: 10.1021/ acs.jmedchem. \\ $5 \mathrm{~b} 00317$. \\ The authors declare no competing financial interest.
}




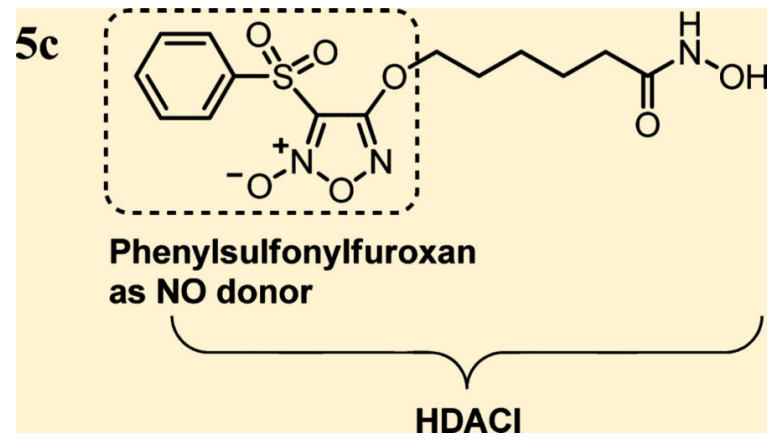

\section{INTRODUCTION}

The important role of histone deacetylation in gene expression and regulation, especially in the pathogenesis of cancer, has been reported by numerous researchers since the 1960s.

Histone deacetylases (HDACs) are a family of enzymes that catalyze acetyl group removal from lysine residues in histone tails and lead to a transcriptionally repressed chromatin state. ${ }^{1,2}$ Abnormal HDAC activity has been found to be associated with the aberrant gene expression and the development of several kinds of cancer and other human ailments. 3,4 Accordingly, HDAC inhibition restores the normal gene expression profile, resulting in cancer cell cycle arrest, cell differentiation, and apoptosis. Thus, HDAC inhibitors (HDACIs, Figure 1), ${ }^{3,5}$ which block abnormal HDAC deacetylation, have been recently developed and validated as potential anticancer agents, including hydroxamic acids, shortchain fatty acids, cyclic tetrapeptide, and benzamides. Among these HDACIs, hydroxamic acids are the most well-known, with SAHA (6, Figure 1), PXD-101 (7, Figure 1), and LBH-589 (8, Figure 1) approved by the U.S. Food and Drug Administration (FDA) in October 2006, July 2014, and February 2015, respectively, for the treatment of cancer ${ }^{6,7}$ in the clinic. Many other hydroxamate compounds are in clinical trials, such as SB-939 (9, phase II, Figure 1) and 4SC-201 (10, phase II, Figure 1). ${ }^{3,8}$

Cellular nitric oxide (NO), described in 1980 by Furchgott, ${ }^{9}$ participates in vascular regulation, nerve transmission delivery, inflammation, and immune responses as an important messenger molecule in an organism. ${ }^{10,11} \mathrm{NO}$ can also inhibit tumor cell proliferation, ${ }^{12}$ angiogenesis, and metastasis ${ }^{13}$ and can accelerate tumor cell apoptosis. ${ }^{14}$ In addition to inducible nitric oxide synthase (iNOS), which can produce a large dose of cellular NO in response to stimulating factors such as cytokines, a chemical NO donor is also an effective way to generate a high concentration of cellular NO. It was reported that glyceryl trinitrate (GTN) can inhibit the proliferation of P388 and L-1210 tumor cells in vitro and in vivo. ${ }^{15}$ Sodium nitroprusside (SNP) was reported to exhibit potential cytotoxicity to ML, AML, and CMMOL leukemia cells. ${ }^{16}$ In 2008, oxadiazole (22, Figure 2) was identified through a high-throughput screen to be an important and potential NO donor, which could produce high levels of NO in vitro and inhibit tumor growth in vivo. ${ }^{17,18}$ Phenylsulfonylfuroxan (23, Figure 2), a classical type of oxadiazole, is stable under acidic and basic conditions, and its mechanism of NO release in vivo was determined to be through its reaction with mercapto compounds such as cysteine, as described by Feelisch in 1992. ${ }^{19}$ It can also release NO to produce activity in variety of tissues and organs through a 
nonenzymatic pathway. Compounds like phenylsulfonylfuroxan coupled with oleanolic acid, farnesylthiosalicylic acid, or anilinopyrimidine have displayed synergistic antitumor activity. ${ }^{20-23}$

Over recent decades, an increasing body of research has indicated that covalent modifications, such as S-nitrosylation or tyrosine nitration of proteins by NO, can dramatically influenced cellular functions. Interestingly, many HDAC family members have also been found to be direct or indirect targets of $\mathrm{NO},{ }^{24}$ and several reports have illustrated NO-dependent regulation of HDAC functions. ${ }^{25}$ The HDAC family consists of 18 isoforms ${ }^{2,3}$ belonging to four structurally and functionally different phylogenetic classes: class I (HDAC 1, 2, 3, and 8), class II (class IIa: HDAC 4, 5, 7, and 9; class IIb: HDAC 6 and 10), and class IV (HDAC 11) are called classical HDACs and are $\mathrm{Zn}^{2+}$-dependent proteases, whereas class III (SIRT 1-7) HDACs are $\mathrm{NAD}^{+}$-dependent. The activity of class I enzymes HDAC 2 and 8 has been reported to be directly inhibited by NO-dependent Snitrosylation. ${ }^{25,26} \mathrm{~S}$-Nitrosylation of HDAC2 induces its release from chromatin. ${ }^{27}$ The nuclear shuttling of class IIa HDACs is also induced by NO through the sGC-cGMP pathway. ${ }^{24}$ Furthermore, NO has been shown to allow crosstalk between class III and class I HDACs. ${ }^{28}$ In fact, some studies have shown that HDACI and NO are synergistic in cardiac hypertrophy ${ }^{29}$ and wound healing. ${ }^{30,31}$

Creating multifunctional drugs through a hybridization strategy is a well-developed approach in drug design. It involves the combination of two complementary or synergistic pharmacophores directly or via a spacer in order to act on different targets to improve the activity. Recently, a hybrid (NO-MS275, 25, Figure 3) of an NO donor and HDACI MS275 (24, Figure 3) was reported to promote myogenic differentiation in a more efficient manner than the 1:1 mixture of the two components $;{ }^{34}$ however, no antitumor activity of this compound was reported. On the basis of the above-mentioned analysis and the multifunctional drugs theory, the goal of this study is to develop a novel HDACI containing an NO donor motif (Figure 4) that exhibits additive antitumor activity via HDAC inhibition and NO release.

\section{RESULTS AND DISCUSSION}

\section{Chemistry}

On the basis of the HDACI pharmacophore exemplified by SAHA (Figure 3), a series of novel target compounds containing phenylsulfonylfuroxan as a NO-donating module was designed and synthesized. Target compounds 5a-5o were synthesized from (phenylthio)acetic acid (purchased from Adamas-beta, China), as shown in Scheme 1. Compounds $\mathbf{2}$ and $\mathbf{3}$ were synthesized following the method of Zhang. ${ }^{23}$ A one-pot reaction of (phenylthio)acetic acid by oxidization with a $30 \% \mathrm{H}_{2} \mathrm{O}_{2}$ aqueous solution resulted in compound $\mathbf{1}$, which was refluxed after adding fuming $\mathrm{HNO}_{3}$ without purification to obtain compound 2. After nucleophilic substitution by several corresponding linkers with two hydroxyl groups, we synthesized various monophenylsulfonylfuroxans (compounds 3a-3n), which were oxidized under Jones reagent to obtain compounds $\mathbf{4 a - 4 n}$. Target compounds 5a-5n were obtained from $\mathbf{4 a}-\mathbf{4 n}$ under conditions of isobutyl chlorocar-bonate, triethylamine, and hydroxylamine hydrochloride. Compound $\mathbf{3} \mathbf{j}$ was also oxidized by PCC 
to produce compound $\mathbf{6}$, which was reacted with propandioic accid to obtain compound 7 and was then transformed to target hydroxamate $\mathbf{5 o .}$

\section{Biological Results}

Inhibiton of HeLa Cell Extracts by the Target Compounds-On the basis of the fact that all zinc ion-dependent HDACs are highly conserved in their active sites, all target compounds were evaluated for their in vitro HDAC inhibitory activities using HeLa cell extracts (containing primarily HDAC 1 and 2) as the enzyme source and SAHA as a positive control. The results, listed in Table 1 , revealed that the $\mathrm{IC}_{50}$ values of compounds $\mathbf{5 a}(0.047$ $\mu \mathrm{M}), \mathbf{5 c}(0.038 \mu \mathrm{M}), \mathbf{5 d}(0.054 \mu \mathrm{M}), \mathbf{5 e}(0.063 \mu \mathrm{M})$, and $\mathbf{5 j}(0.047 \mu \mathrm{M})$ were significantly lower than that of SAHA. This result revealed that compounds containing a saturated fatty linker without any branched chains were more potent than those with other linkers. When the linker was substituted with an aromatic ring such as benzene, the $\mathrm{IC}_{50}$ values of those without this substitution were lower than analogues with it, and the hydroximic acid group was best located para to the phenylsulfonylfuroxan. Generally, compounds containing saturated fatty linkers without any branched chains exhibited much greater potency in their HDAC inhibitory activity, and the optimal length of the linker should be six to eight carbons. Our results also showed that compounds $\mathbf{2}$ and $\mathbf{3 c}$ were not active against HeLa cell nuclear extracts, validating the crucial role of the hydroxamate group in HDAC inhibition.

In Vitro Antiproliferative Assay-Antiproliferative activities of target compounds 5a$\mathbf{5 o}$ and 3c, $\mathbf{2}$, and SAHA with $\mathbf{2}$ (1:1) were tested against HEL (human erythrocyte leukemia cell), HCT-116 (human colorectal carcinoma cell), HeLa (human cervical carcinoma cell), U937 (human histiocytic leukemia cell line), 3-AO (human oophoroma cell), MDA (human breast cancer cell), ES-2 (ovarian clear cell carcinoma cell), and KG1 (human leukemia cell) cell lines by an MTT (3-(4,5-dimethylthiazol-2-yl)-2,5-diphenyltetrazolium bromide) reduction assay, using SAHA as the positive control (Table 2). From the result listed in Table 2, it was found that the inhibitory activity against tumor cell growth of most of these compounds was better than that of the clinically approved drug SAHA, especially $\mathbf{5 a}, \mathbf{5 b}$, $\mathbf{5 c}$, and $\mathbf{5 j}$, which exhibited higher HDAC enzyme inhibitory potency with improved antiproliferative ability against cancerous cells. It should be noted that NO donors $\mathbf{2}$ and $\mathbf{3 c}$ were also effective against HEL cell proliferation and that the combination of SAHA and NO donor 2 at a mole ratio of 1:1 exhibited a dramatic additive effect. In addition, the cytotoxicity of $\mathbf{5 c}$ against normal primary HUVECs (human umbilical vein endothelial cells) was tested in our lab, and the $\mathrm{IC}_{50}$ value was $27.1 \mu \mathrm{M}$, which revealed our compounds' selectivity over nontransformed cells when compared to tumor cells. Encouraged by these results, compound $\mathbf{5 c}$, with the highest HeLa nuclear extract inhibitory potency and the best antiproliferative activity, was progressed to further in vitro evaluation using the most sensitive HEL cell line as a cellular model.

NO Generation Measurement-Regarding the effect of NO generation, the levels of NO generated by the tested compounds in vitro were detected. HEL cells were exposed to $100 \mu \mathrm{M} \mathbf{5 a}, \mathbf{5 b}, \mathbf{5 c}, \mathbf{5 j}, \mathbf{2}$, or SAHA for the same incubation time ( 3 or $5 \mathrm{~h}$ ). The levels of NO released in the cell lysates were determined using a Griess assay. In Figure 5, we found that the compounds we designed and synthesized could promote the release of NO effectively; in 
contrast, SAHA hardly promoted any release of NO in HEL cells. Compound $\mathbf{5 c}$, which exhibited the most potent activity against HDACs and tumor cells, also promoted the most NO release among the tested compounds.

In Vitro Antiproliferative Assay with Hemoglobin-In order to verify that the proliferation of tumor cells was also inhibited by NO generated from our compounds, we further examined the antiproliferative effects of $\mathbf{5 c}$ in the presence or absence of an NO scavenger, hemoglobin $(\mathrm{Hb})$. HEL cells were pretreated with the indicated concentrations of NO scavenger hemoglobin $(0,2.5,5,10$, and $20 \mu \mathrm{M})$ for $1 \mathrm{~h}$ and then treated with $2 \mu \mathrm{M} \mathbf{5 c}$ for $24 \mathrm{~h}$. The results were expressed as the percentage of growth inhibition relative to the control cells in Figure 6. It was observed that $\mathbf{5 c}$ remarkably inhibited the growth of HEL cells and that this inhibitory effect was diminished by pretreatment with hemoglobin in a dose-dependent manner. These results demonstrated that NO produced in response to $\mathbf{5 c}$ contributed, in part, to its inhibition of tumor cell proliferation, which validated our compound design strategy.

Induction of Apoptosis in Vitro-As the fact that high levels of NO act as a tumor cell apoptosis inducer, the ability of $\mathbf{5 c}$, as a NO donor, to induce tumor cell apoptosis was tested and compared with that of SAHA. HEL cells were treated with variable amounts of $\mathbf{5 c}$,

SAHA, and 2 for $24 \mathrm{~h}$. The cells were harvested and stained with 7-aminoactinomycin D (7$\mathrm{AAD}$ ) and annexin- $\mathrm{V}$, and the percentage of apoptotic cells was determined by flow cytometry analysis. Notably, it was found that the ability of $5 \mathrm{c}$ to induce apoptosis was stronger than that of SAHA in HEL cells (Figure 7A) and that the rate of apoptosis increased in a dose-dependent manner (Figure 7B).

Cell Cycle Arrest Analysis-The effect of $\mathbf{5 c}$ on the various phases of the cell cycle was tested in HEL cells (Figure 8). In comparison to the control population, the cell cycle data clearly showed that $\mathbf{5 c}$ arrested HEL cells mainly in G1 phase (90.24\%), which was stronger than that of SAHA $(79.98 \%)$.

In Vivo Antitumor Activity-Compound $\mathbf{5 c}$ was further evaluated for its in vivo antitumor efficacy in a HEL xenograft mouse model. Compound $\mathbf{5 c}$ (100 or $120 \mathrm{mg} / \mathrm{kg} / \mathrm{day})$ and SAHA $(120 \mathrm{mg} / \mathrm{kg} / \mathrm{day})$ were dosed orally by gavage for 21 consecutive days. Tumor growth inhibition (TGI) and relative increment ratio $(T / C)$ were calculated as described previously ${ }^{32}$ at the end of treatment to reveal the antitumor effects with respect to tumor weight and tumor volume (Table 3).

In the HEL xenograft model, compound $\mathbf{5 c}$ exhibited dose-dependent antitumor activity, and at the same dosage of $120 \mathrm{mg} / \mathrm{kg} /$ day, compound $\mathbf{5 c}$ demonstrated superior antitumor activity (TGI $=48 \%, T / C=39 \%$ ) to that of the reference compound, SAHA (TGI $=39 \%$, $T / C=46 \%)$. The tumor growth curve depicted in Figure 9 and the final tumor tissue size visualized in Figure 10 also explicitly showed the excellent antitumor potency of $\mathbf{5 c}$. Importantly, mice treated with a higher dose of $\mathbf{5 c}(120 \mathrm{mg} / \mathrm{kg})$ showed no significant body weight loss (Figure 11) and no evidence of liver or spleen toxicity. 
In Vitro HDAC Isoform Selectivity of $\mathbf{5 c}$-In order to explore its HDAC isoform selectivity profile, $\mathbf{5} \mathbf{c}$ was tested for its inhibitory activity of $\operatorname{HDAC} 1,2,3,4,6,8$, and 11 (Table 4). From the results, we found that at the molecular level compound $\mathbf{5 c}$ exhibited remarkable selectivity for HDAC 6 over other isoforms.

Western Blot Analysis-In order to investigate its HDAC isoform selectivity in a cellular environment, compound $\mathbf{5 c}$ was further evaluated in western blot assays to determine the levels of acetylated protein (Figure 12). The results in Figure 12A showed that at a very low concentration of $12.5 \mathrm{nM}$ compound $\mathbf{5 c}$ could still dramatically increase the cellular level of actubulin, the substrate of HDAC 6, which was in line with its highly potent HDAC 6 inhibitory activity ( $\mathrm{IC}_{50}$ of $\left.7 \mathrm{nM}\right)$. However, $\mathbf{5 c}$ could also effectively increase cellular levels of AcHH3 and AcHH4, which are the main nuclear substrates of HDAC 1 and 2. This is not very surprising because $\mathbf{5 c}$ could promote the release NO effectively and some research has shown that NO not only could inhibit the enzyme activity ${ }^{25}$ and chromatin binding of HDAC 2 by S-nitrosylation ${ }^{27}$ but also could minimally inhibit HDAC1 by an S-nitrosylation-independent mechanism. ${ }^{25}$ Moreover, our results also showed that $\mathbf{5 c}$ could decrease the cellular level of HDAC 2 at higher concentrations ( 1 and $10 \mu \mathrm{M}$, Figure 12B), which could also be attributed to release of NO because the NO scavenger PTIO could recover the cellular level of HDAC 2 (Figure 12C). Additional research to elucidate the mechanism of how NO affects cellular levels of HDAC 2 is warranted.

\section{CONCLUSIONS}

In the present research, a novel series of compounds capable of simultaneously promoting the release NO and inhibiting HDACs was designed and synthesized for the treatment of cancer based on the multifunctional drug approach. All synthesized compounds were evaluated for their HDAC inhibitory potency against HeLa cell nuclear extracts as well as for their antiproliferative effects against several tumor cell lines. Several representative compounds were evaluated in the HEL cell line and displayed potent NO releasing activity, with compound $\mathbf{5 c}$ being the most potent of those evaluated. Pretreatment of HEL cells with the NO scavenger hemoglobin moderately reduced the antiproliferative activity of $\mathbf{5 c}$, demonstrating the additive effect between NO release and HDAC inhibition. Further mechanistic studies revealed that 5c induced a much stronger apoptotic effect and G1 phase arrest in HEL cells than that of SAHA, which was in line with its ability to inhibit HDACs and to generate NO. Because of its very promising in vitro activity, compound $\mathbf{5 c}$ was progressed to a HEL xenograft model and exhibited greater oral antitumor potency than SAHA in a dose-dependent manner. It is worth noting that compound $\mathbf{5 c}$ was a remarkably HDAC 6-selective inhibitor at the molecular level, which could be used as a design template for HDAC 6-selective inhibitors. Taken together, compound $\mathbf{5 c}$, a very potent HDAC inhibitor with NO releasing activity, was discovered and deserves further research and development as a promising therapeutic agent for hematologic malignancies. 


\section{EXPERIMENTAL SECTION}

\section{Chemistry Materials and Methods}

All commercially available starting materials, reagents, and solvents were used without further purification unless otherwise stated. All reactions were monitored by TLC with 0.25 $\mathrm{mm}$ silica gel plates (60GF-254). UV light, iodine stain, and ferric chloride were used to visualize the spots. Silica gel or C18 silica gel was used for column chromatography purification. ${ }^{1} \mathrm{H}$ and ${ }^{13} \mathrm{C}$ NMR spectra were recorded on a Bruker DRX spectrometer at 600 $\mathrm{MHz}$, with $\delta$ given in parts per million and $J$ in hertz and using TMS as an internal standard. High-resolution mass spectra were conducted by Shandong Analysis and Test Center in Ji'nan, China. ESI-MS spectra were recorded on an API 4000 spectrometer. Melting points were determined uncorrected on an electrothermal melting point apparatus. All tested compounds are $>95 \%$ pure by HPLC analysis, performed on a Agilent 1100 HPLC instrument using an $5 \mu \mathrm{m}$ ODS HYPERSIL column $(4.6 \mathrm{~mm} \times 250 \mathrm{~mm})$ according to the following methods. All target compounds were eluted with $35 \%$ acetonitrile/65\% water (containing $0.1 \%$ acetic acid) over $20 \mathrm{~min}$, with detection at $254 \mathrm{~nm}$ and a flow rate of 1.0 $\mathrm{mL} / \mathrm{min}$.

\section{Synthesis of Compound 2 (3,4-Bis(phenylsulfonyl)-1,2,5-oxadiazole 2-Oxide)}

-To a solution of (phenylthio)acetic acid $(10.0 \mathrm{~g}, 55.0 \mathrm{mmol})$ in glacial acetic acid $(16 \mathrm{~mL})$ was added aqueous $\mathrm{H}_{2} \mathrm{O}_{2}(30 \%, 13.6 \mathrm{~mL})$ at $0{ }^{\circ} \mathrm{C}$; after $1.0 \mathrm{~h}$ of stirring at room temperature, the mixture was stirred at $80^{\circ} \mathrm{C}$ for $3 \mathrm{~h}$ after fuming with nitric acid $(24 \mathrm{~mL})$ while controlling the inner temperature to be lower than $20^{\circ} \mathrm{C}$. The reaction was checked by TLC, and the mixture was cooled after it reacted completely; then, compound $\mathbf{2}$ was collected by filtration and dried under vacuum to give a white solid (yield: 56\%). ${ }^{1} \mathrm{H}$ NMR $\left(400 \mathrm{MHz}, \mathrm{CDCl}_{3}\right)^{20} \delta 8.20(\mathrm{t}, J=7.4 \mathrm{~Hz}, 4 \mathrm{H}), 7.83(\mathrm{dd}, J=14.3,7.3 \mathrm{~Hz}, 2 \mathrm{H}), 7.69(\mathrm{dt}, J=$ $16.1,8.2 \mathrm{~Hz}, 4 \mathrm{H})$.

\section{General Procedure for the Preparation of Compounds 3a-3o}

4-(4-Hydroxybutoxy)-3-(phenylsulfonyl)-1,2,5-oxadiazole 2-Oxide (3a)-To a solution of compound $2(1.1 \mathrm{~g}, 2.7 \mathrm{mmol})$ in $10 \mathrm{~mL}$ of THF was added 1,4-butanediol (1.2 $\mathrm{mL}, 11.4 \mathrm{mmol}$ ) at approximately $5^{\circ} \mathrm{C}$, followed by the dropwise addition of $2.5 \mathrm{~N}$ aqueous $\mathrm{NaOH}(1 \mathrm{~mL})$ and $30 \mathrm{~min}$ stirring. The solution was concentrated under vacuum at room temperature. The residue was extracted with EtOAc three times $(3 \times 50 \mathrm{~mL})$ and washed twice with water and brine. The combined organic layers were dried by anhydrous $\mathrm{Na}_{2} \mathrm{SO}_{4}$ and evaporated under vacuum to give a residue that was purified by silica-gel column chromatography, resulting in a white solid product (yield: 71\%). ${ }^{1} \mathrm{H} \mathrm{NMR}(400 \mathrm{MHz}$, $\left.\mathrm{CDCl}_{3}\right)^{32} \delta 8.05(\mathrm{~d}, J=7.7 \mathrm{~Hz}, 2 \mathrm{H}), 7.76(\mathrm{t}, J=7.3 \mathrm{~Hz}, 1 \mathrm{H}), 7.62(\mathrm{t}, J=7.6 \mathrm{~Hz}, 2 \mathrm{H}), 4.47$ (t, $J=6.1 \mathrm{~Hz}, 2 \mathrm{H}), 3.76(\mathrm{t}, J=6.1 \mathrm{~Hz}, 2 \mathrm{H}), 2.07-1.91(\mathrm{~m}, 2 \mathrm{H}), 1.82-1.71(\mathrm{~m}, 2 \mathrm{H}), 1.62(\mathrm{~s}$, $1 \mathrm{H})$.

4-((5-Hydroxypentyl)oxy)-3-(phenylsulfonyl)-1,2,5-oxadiazole 2-Oxide (3b)White solid (yield: 66\%). ${ }^{1} \mathrm{H}$ NMR $\left(600 \mathrm{MHz}\right.$, DMSO- $\left.d_{6}\right){ }^{33} \delta 8.02(\mathrm{~d}, J=7.7 \mathrm{~Hz}, 2 \mathrm{H}), 7.91$ (t, $J=7.4 \mathrm{~Hz}, 1 \mathrm{H}), 7.76$ (t, $J=7.5 \mathrm{~Hz}, 2 \mathrm{H}), 4.39(\mathrm{t}, J=6.2 \mathrm{~Hz}, 2 \mathrm{H}), 3.42(\mathrm{t}, J=6.2 \mathrm{~Hz}, 2 \mathrm{H})$, 1.79-1.72 (m, 2H), 1.50-1.44 (m, 2H), 1.42-1.37 (m, 2H). 4-((6-Hydroxyhexyl)oxy)-3- 
(phenylsulfonyl)-1,2,5-oxadiazole 2-oxide (3c): white solid (yield: 73\%). ${ }^{1} \mathrm{H}$ NMR (600 MHz, DMSO- $\left.d_{6}\right)^{33} \delta 8.02(\mathrm{~d}, J=7.7 \mathrm{~Hz}, 2 \mathrm{H}), 7.91(\mathrm{t}, J=7.3 \mathrm{~Hz}, 1 \mathrm{H}), 7.76(\mathrm{t}, J=7.8 \mathrm{~Hz}$, $2 \mathrm{H}), 4.38(\mathrm{t}, J=6.3 \mathrm{~Hz}, 2 \mathrm{H}), 3.98(\mathrm{t}, J=6.7 \mathrm{~Hz}, 2 \mathrm{H}), 1.79-1.71(\mathrm{~m}, 2 \mathrm{H}), 1.58-1.52(\mathrm{~m}, 2 \mathrm{H})$, $1.35(\mathrm{~d}, J=3.1 \mathrm{~Hz}, 2 \mathrm{H}), 1.29(\mathrm{~d}, J=3.1 \mathrm{~Hz}, 2 \mathrm{H})$.

4-((7-Hydroxyheptyl)oxy)-3-(phenylsulfonyl)-1,2,5-oxadiazole 2-Oxide (3d)White solid (yield: 66\%). ${ }^{1} \mathrm{H}$ NMR $\left(600 \mathrm{MHz}, \mathrm{CDCl}_{3}\right) \delta 8.05(\mathrm{~d}, J=7.8 \mathrm{~Hz}, 2 \mathrm{H}), 7.74(\mathrm{t}, J$ $=7.5 \mathrm{~Hz}, 1 \mathrm{H}), 7.61(\mathrm{t}, J=7.7 \mathrm{~Hz}, 2 \mathrm{H}), 4.42(\mathrm{t}, J=6.5 \mathrm{~Hz}, 2 \mathrm{H}), 3.66(\mathrm{t}, J=6.6 \mathrm{~Hz}, 2 \mathrm{H})$, $1.91-1.84(\mathrm{~m}, 2 \mathrm{H}), 1.59(\mathrm{dd}, J=13.0,6.5 \mathrm{~Hz}, 2 \mathrm{H}), 1.50-1.46(\mathrm{~m}, 2 \mathrm{H}), 1.42(\mathrm{dd}, J=6.5,3.5$ $\mathrm{Hz}, 4 \mathrm{H}) .{ }^{13} \mathrm{C}$ NMR $\left(151 \mathrm{MHz}, \mathrm{CDCl}_{3}\right) \delta 159.2,138.4,135.7,129.8,129.3,128.7,128.0$, 110.6, 71.7, 63.0, 32.7, 29.0, 28.4, 25.7, 25.7. ESI-MS $[\mathrm{M}+\mathrm{H}]^{+} \mathrm{m} / z: 357.1$.

4-((8-Hydroxyoctyl)oxy)-3-(phenylsulfonyl)-1,2,5-oxadiazole 2-Oxide (3e)White solid (yield: $71 \%) .{ }^{1} \mathrm{H}$ NMR $\left(600 \mathrm{MHz}, \mathrm{CDCl}_{3}\right) \delta 8.04(\mathrm{~d}, J=7.8 \mathrm{~Hz}, 2 \mathrm{H}), 7.75(\mathrm{t}, J$ $=7.5 \mathrm{~Hz}, 1 \mathrm{H}), 7.61(\mathrm{t}, J=7.6 \mathrm{~Hz}, 2 \mathrm{H}), 4.40(\mathrm{t}, J=6.5 \mathrm{~Hz}, 2 \mathrm{H}), 3.62(\mathrm{~s}, 2 \mathrm{H}), 1.88-1.82(\mathrm{~m}$, $2 \mathrm{H}), 1.65-1.49(\mathrm{~m}, 8 \mathrm{H}), 1.44(\mathrm{dd}, J=13.6,6.4 \mathrm{~Hz}, 2 \mathrm{H}) .{ }^{13} \mathrm{C} \mathrm{NMR}\left(151 \mathrm{MHz}, \mathrm{CDCl}_{3}\right) \delta$ 159.1, 138.1, 135.6, 129.6, 129.2, 128.5, 127.8, 110.5, 71.6, 62.9, 32.7, 29.2, 29.0, 28.4, 25.6, 25.6, 25.5. ESI-MS $[\mathrm{M}+\mathrm{H}]^{+} \mathrm{m} / z: 371.1$.

4-(2-(2-Hydroxyethoxy)ethoxy)-3-(phenylsulfonyl)-1,2,5-oxadiazole 2-Oxide (3f) -White solid (yield: 56\%). ${ }^{1} \mathrm{H}$ NMR $\left(400 \mathrm{MHz}, \mathrm{CDCl}_{3}\right)^{33} \delta 8.06(\mathrm{~d}, J=7.7 \mathrm{~Hz}, 2 \mathrm{H}), 7.75$ (t, $J=7.5 \mathrm{~Hz}, 1 \mathrm{H}), 7.61(\mathrm{t}, J=7.8 \mathrm{~Hz}, 2 \mathrm{H}), 4.62-4.51(\mathrm{~m}, 2 \mathrm{H}), 3.97-3.89(\mathrm{~m}, 2 \mathrm{H}), 3.81-3.74$ $(\mathrm{m}, 2 \mathrm{H}), 3.72-3.67(\mathrm{~m}, 2 \mathrm{H})$.

4-(3-Hydroxy-2,2-dimethylpropoxy)-3-(phenylsulfonyl)-1,2,5-oxadiazole 2Oxide (3g)—White solid (yield: 80\%). ${ }^{1} \mathrm{H}$ NMR $\left(400 \mathrm{MHz}, \mathrm{CDCl}_{3}\right) \delta 8.04(\mathrm{~d}, J=8.0 \mathrm{~Hz}$, 2H), $7.75(\mathrm{t}, J=7.1 \mathrm{~Hz}, 1 \mathrm{H}), 7.61(\mathrm{t}, J=7.7 \mathrm{~Hz}, 2 \mathrm{H}), 4.23(\mathrm{~s}, 2 \mathrm{H}), 3.55(\mathrm{~s}, 2 \mathrm{H}), 1.05$ (s, $6 \mathrm{H}) .{ }^{13} \mathrm{C} \mathrm{NMR}\left(400 \mathrm{MHz}, \mathrm{CDCl}_{3}\right) \delta 153.5,137.4,132.6,132.1,127.6,76.7,69.6,37.1$, 19.4. ESI-MS $[\mathrm{M}+\mathrm{H}]^{+} m / z: 329.1$.

(E)-4-((4-Hydroxybut-2-en-1-yl)oxy)-3-(phenylsulfonyl)-1,2,5-oxadiazole 2Oxide (3h)—White solid (yield: 70\%). ${ }^{1} \mathrm{H}$ NMR $\left(600 \mathrm{MHz}, \mathrm{CDCl}_{3}\right) \delta 8.12-8.02(\mathrm{~m}, 2 \mathrm{H})$, 7.96-7.87 (m, 1H), 7.81-7.69 (m, 2H), 5.98-5.77 (m, 2H), $4.68(\mathrm{dd}, J=11.5,1.0 \mathrm{~Hz}, 2 \mathrm{H})$, 4.23-4.11 (m, 2H). $\left.{ }^{13} \mathrm{C} \mathrm{NMR} \mathrm{(400} \mathrm{MHz,} \mathrm{CDCl}_{3}\right) \delta 155.5,137.4,132.6,132.1,131.7,128.1$, 127.6, 69.6, 63.3. ESI-MS $[\mathrm{M}+\mathrm{H}]^{+} \mathrm{m} / \mathrm{z}: 313.0$.

4-(2-(2-(2-Hydroxyethoxy)ethoxy)ethoxy)-3-(phenylsulfonyl)-1,2,5-oxadiazole 2-Oxide (3i)—White solid (yield: 58\%). ${ }^{1} \mathrm{H}$ NMR $\left(600 \mathrm{MHz}, \mathrm{CDCl}_{3}\right)^{20} \delta 8.03$ (d, $J=7.6$ $\mathrm{Hz}, 2 \mathrm{H}), 7.90$ (d, $J=7.5 \mathrm{~Hz}, 1 \mathrm{H}), 7.76(\mathrm{t}, J=7.9 \mathrm{~Hz}, 2 \mathrm{H}), 4.53-4.50(\mathrm{~m}, 2 \mathrm{H}), 3.81-3.79$ (m, $2 \mathrm{H}), 3.64-3.61(\mathrm{~m}, 2 \mathrm{H}), 3.57-3.54(\mathrm{~m}, 2 \mathrm{H}), 3.49$ (d, $J=5.3 \mathrm{~Hz}, 2 \mathrm{H}), 3.43(\mathrm{~d}, J=5.0 \mathrm{~Hz}$, $2 \mathrm{H})$.

4-(4-(Hydroxymethyl)phenoxy)-3-(phenylsulfonyl)-1,2,5-oxadiazole 2-Oxide (3j) -White solid (yield: 68\%). ${ }^{1} \mathrm{H}$ NMR $\left(600 \mathrm{MHz}, \mathrm{DMSO}-d_{6}\right)^{20} \delta 8.06(\mathrm{~d}, J=7.9 \mathrm{~Hz}, 2 \mathrm{H})$, $7.93(\mathrm{t}, J=7.3 \mathrm{~Hz}, 1 \mathrm{H}), 7.78(\mathrm{t}, J=7.6 \mathrm{~Hz}, 2 \mathrm{H}), 7.43(\mathrm{~d}, J=8.3 \mathrm{~Hz}, 2 \mathrm{H}), 7.37(\mathrm{~d}, J=8.3$ $\mathrm{Hz}, 2 \mathrm{H}), 5.27(\mathrm{t}, J=5.7 \mathrm{~Hz}, 1 \mathrm{H})$. 
4-(3-(Hydroxymethyl)phenoxy)-3-(phenylsulfonyl)-1,2,5-oxadiazole 2-Oxide (3k)—White solid (yield: 74\%). ${ }^{1} \mathrm{H}$ NMR $\left(600 \mathrm{MHz}, \mathrm{DMSO}-d_{6}\right)^{20} \delta 8.05(\mathrm{~d}, J=7.7 \mathrm{~Hz}$, 2H), $7.91(\mathrm{t}, J=7.5 \mathrm{~Hz}, 1 \mathrm{H}), 7.77(\mathrm{t}, J=7.8 \mathrm{~Hz}, 2 \mathrm{H}), 7.43(\mathrm{t}, J=7.9 \mathrm{~Hz}, 1 \mathrm{H}), 7.35(\mathrm{~s}, 1 \mathrm{H})$, $7.27(\mathrm{dd}, J=11.4,9.1 \mathrm{~Hz}, 2 \mathrm{H}), 5.27(\mathrm{t}, J=5.5 \mathrm{~Hz}, 1 \mathrm{H}), 4.54(\mathrm{~d}, J=5.1 \mathrm{~Hz}, 2 \mathrm{H})$.

4-(4-(Hydroxymethyl)-2-methoxyphenoxy)-3-(phenylsulfonyl)-1,2,5-oxadiazole 2-Oxide (3I)—White solid (yield: 67\%). ${ }^{1} \mathrm{H}$ NMR (600 MHz, $\left.\mathrm{CDCl}_{3}\right) \delta 8.09$ (d, $J=8.2 \mathrm{~Hz}$, $2 \mathrm{H}), 7.95(\mathrm{t}, J=7.4 \mathrm{~Hz}, 1 \mathrm{H}), 7.81(\mathrm{t}, J=7.7 \mathrm{~Hz}, 2 \mathrm{H}), 7.36(\mathrm{~d}, J=8.2 \mathrm{~Hz}, 1 \mathrm{H}), 7.17(\mathrm{~s}, 1 \mathrm{H})$, $6.98(\mathrm{~d}, J=8.2 \mathrm{~Hz}, 1 \mathrm{H}), 5.31(\mathrm{~d}, J=5.7 \mathrm{~Hz}, 1 \mathrm{H}), 4.53(\mathrm{~d}, J=5.8 \mathrm{~Hz}, 2 \mathrm{H}), 3.72(\mathrm{~s}, 3 \mathrm{H}) .{ }^{13} \mathrm{C}$ NMR (400 MHz, $\left.\mathrm{CDCl}_{3}\right) \delta 155.3,150.9,137.4,136.6,132.6,132.1,128.2,127.6,120.7$, 63.2, 39.4. ESI-MS $[\mathrm{M}+\mathrm{H}]^{+} \mathrm{m} / z: 379.1$.

4-(4-(2-Hydroxyethyl)phenoxy)-3-(phenylsulfonyl)-1,2,5-oxadiazole 2-Oxide (3m)-Colorless oil (yield: 61\%). ${ }^{1} \mathrm{H}$ NMR $\left(600 \mathrm{MHz}, \mathrm{CDCl}_{3}\right) \delta 8.06(\mathrm{~d}, J=8.1 \mathrm{~Hz}, 2 \mathrm{H})$, $7.92(\mathrm{t}, J=7.4 \mathrm{~Hz}, 1 \mathrm{H}), 7.77(\mathrm{t}, J=7.6 \mathrm{~Hz}, 2 \mathrm{H}), 7.32(\mathrm{q}, J=8.6 \mathrm{~Hz}, 4 \mathrm{H}), 4.66(\mathrm{t}, J=5.1$ $\mathrm{Hz}, 1 \mathrm{H}), 3.64(\mathrm{dd}, J=12.4,6.3 \mathrm{~Hz}, 2 \mathrm{H}), 2.76(\mathrm{t}, J=6.8 \mathrm{~Hz}, 2 \mathrm{H}) .{ }^{13} \mathrm{C} \mathrm{NMR}(400 \mathrm{MHz}$, $\left.\mathrm{CDCl}_{3}\right) \delta 154.3,137.4,132.6,132.1,127.6,72.6,70.4,70.0,66.6,61.0$. ESI-MS [M + H] ${ }^{+}$ $\mathrm{m} / \mathrm{z}: 363.1$.

4-((2-(Hydroxymethyl)-2-methylpentyl)oxy)-3-(phenylsulfonyl)-1,2,5-oxadiazole 2-Oxide (3n)—Colorless oil (yield: 63\%). ${ }^{1} \mathrm{H}$ NMR $\left(600 \mathrm{MHz}, \mathrm{CDCl}_{3}\right) \delta 8.08-8.01$ (m, 2H), 7.95-7.86 (m, 1H), 7.76-7.68 (m, 2H), 4.27 (dd, $J=172.0,24.7 \mathrm{~Hz}, 2 \mathrm{H}), 3.42$ (dd, $J=$ 127.1, $24.7 \mathrm{~Hz}, 2 \mathrm{H}), 1.49$ (s, 1H), 1.45-1.33 (m, 4H), 0.95 (d, J = 8.4 Hz, 3H), 0.91-0.83 (m, $3 \mathrm{H}) .{ }^{13} \mathrm{C} \mathrm{NMR}\left(400 \mathrm{MHz}, \mathrm{CDCl}_{3}\right) \delta 153.5,137.4,132.6,132.1,127.6,73.7,69.9,38.8$, 34.1, 20.3 17.1, 14.7. ESI-MS [M+ H] ${ }^{+} \mathrm{m} / z: 357.1$.

\section{General Procedure for the Preparation of Compounds 4a-4n}

4-(3-Carboxypropoxy)-3-(phenylsulfonyl)-1,2,5-oxadiazole 2-Oxide (4a)-To a solution of $3(680 \mathrm{mg}, 2.2 \mathrm{mmol})$ in $10 \mathrm{~mL}$ of acetone was added Jones reagent $(1.1 \mathrm{~mL})$ at $0-5{ }^{\circ} \mathrm{C}$. This mixture was stirred at $\mathrm{rt}$ for $10 \mathrm{~h}$. The precipitate was filtered off, acetone was removed in vacuo, EtOAc $(3 \times 50 \mathrm{~mL})$ was added, and the organic portion was washed with water and brine and dried by anhydrous $\mathrm{Na}_{2} \mathrm{SO}_{4}$. The crude product was obtained by removing EtOAc and purified by silica chromatography column $(\mathrm{P} / \mathrm{E}=3: 1)$ to obtain the product as a white solid (yield: $81 \%) .{ }^{1} \mathrm{H} \mathrm{NMR}\left(400 \mathrm{MHz}, \mathrm{CDCl}_{3}\right) \delta 8.05(\mathrm{~d}, J=7.6 \mathrm{~Hz}$, 2H), $7.76(\mathrm{t}, J=7.4 \mathrm{~Hz}, 1 \mathrm{H}), 7.62(\mathrm{t}, J=7.8 \mathrm{~Hz}, 2 \mathrm{H}), 4.50(\mathrm{t}, J=6.0 \mathrm{~Hz}, 2 \mathrm{H}), 2.60(\mathrm{t}, J=$ $7.0 \mathrm{~Hz}, 2 \mathrm{H}), 2.26-2.19(\mathrm{~m}, 2 \mathrm{H}), 2.17(\mathrm{~s}, 1 \mathrm{H}) .{ }^{13} \mathrm{C} \mathrm{NMR}\left(400 \mathrm{MHz}, \mathrm{CDCl}_{3}\right) \delta 177.2,154.3$, 137.4, 132.6, 132.1, 127.6, 68.0, 31.8, 24.3. ESI-MS [M+ H] ${ }^{+} \mathrm{m} / z: 329.0$.

4-(4-Carboxybutoxy)-3-(phenylsulfonyl)-1,2,5-oxadiazole 2-Oxide (4b)-White solid (yield: $80 \%) .{ }^{1} \mathrm{H}$ NMR $\left(600 \mathrm{MHz}, \mathrm{CDCl}_{3}\right) \delta 12.09(\mathrm{~s}, 1 \mathrm{H}), 8.02(\mathrm{~d}, J=8.0 \mathrm{~Hz}, 2 \mathrm{H})$, $7.90(\mathrm{t}, J=7.4 \mathrm{~Hz}, 1 \mathrm{H}), 7.75(\mathrm{t}, J=7.6 \mathrm{~Hz}, 2 \mathrm{H}), 4.40(\mathrm{t}, J=6.0 \mathrm{~Hz}, 2 \mathrm{H}), 2.30(\mathrm{t}, J=7.3 \mathrm{~Hz}$, $2 \mathrm{H}), 1.82-1.74(\mathrm{~m}, 2 \mathrm{H}), 1.62(\mathrm{t}, J=6.4 \mathrm{~Hz}, 2 \mathrm{H}) .{ }^{13} \mathrm{C} \mathrm{NMR}\left(400 \mathrm{MHz}, \mathrm{CDCl}_{3}\right) \delta 177.2$, 154.3, 137.4, 132.6, 132.1, 127.6, 69.3, 34.5, 28.8, 22.1. ESI-MS $[\mathrm{M}+\mathrm{H}]^{+} \mathrm{m} / z: 343.0$. 
4-((5-Carboxypentyl)oxy)-3-(phenylsulfonyl)-1,2,5-oxadiazole 2-Oxide (4c)White solid (yield: 73\%). ${ }^{1} \mathrm{H}$ NMR $\left(600 \mathrm{MHz}\right.$, DMSO- $\left.d_{6}\right) \delta 12.04(\mathrm{~s}, 1 \mathrm{H}), 8.04-8.00(\mathrm{~m}$, $2 \mathrm{H}), 7.91(\mathrm{t}, J=7.4 \mathrm{~Hz}, 1 \mathrm{H}), 7.76(\mathrm{t}, J=7.9 \mathrm{~Hz}, 2 \mathrm{H}), 4.38(\mathrm{t}, J=6.2 \mathrm{~Hz}, 2 \mathrm{H}), 2.24(\mathrm{t}, J=$ $7.3 \mathrm{~Hz}, 2 \mathrm{H}), 1.79-1.71(\mathrm{~m}, 2 \mathrm{H}), 1.58-1.54(\mathrm{~m}, 2 \mathrm{H}), 1.38(\mathrm{dd}, J=15.3,8.0 \mathrm{~Hz}, 2 \mathrm{H}) .{ }^{13} \mathrm{C}$ NMR (400 MHz, $\left.\mathrm{CDCl}_{3}\right) \delta 177.2,154.3,137.4,132.6,132.1,127.6,69.3,34.5,29.3,25.9$, 24.9. ESI-MS $[\mathrm{M}+\mathrm{H}]^{+} \mathrm{m} / z: 357.1$.

4-((6-Carboxyhexyl)oxy)-3-(phenylsulfonyl)-1,2,5-oxadiazole 2-Oxide (4d)White solid (yield: 83\%). ${ }^{1} \mathrm{H}$ NMR $\left(600 \mathrm{MHz}, \mathrm{CDCl}_{3}\right) \delta 11.58(\mathrm{~s}, 1 \mathrm{H}), 8.07(\mathrm{~d}, J=8.0 \mathrm{~Hz}$, $2 \mathrm{H}), 7.78(\mathrm{t}, J=7.5 \mathrm{~Hz}, 1 \mathrm{H}), 7.64(\mathrm{t}, J=7.8 \mathrm{~Hz}, 2 \mathrm{H}), 4.43(\mathrm{t}, J=6.4 \mathrm{~Hz}, 2 \mathrm{H}), 2.38$ (d, $J=$ $7.4 \mathrm{~Hz}, 2 \mathrm{H}), 1.94-1.85(\mathrm{~m}, 2 \mathrm{H}), 1.69(\mathrm{dd}, J=14.8,7.3 \mathrm{~Hz}, 4 \mathrm{H}), 1.48-1.43(\mathrm{~m}, 2 \mathrm{H}) .{ }^{13} \mathrm{C}$ NMR $\left(400 \mathrm{MHz}, \mathrm{CDCl}_{3}\right) \delta 180.0,159.0,138.1,135.6,129.7,129.2,128.5,127.8,110.5$, 71.4, 33.8, 28.5, 28.2, 25.3, 24.2. ESI-MS [M+ H] ${ }^{+} \mathrm{m} / z: 371.1$.

4-((7-Carboxyheptyl)oxy)-3-(phenylsulfonyl)-1,2,5-oxadiazole 2-Oxide (4e)White solid (yield: 79\%). ${ }^{1} \mathrm{H}$ NMR $\left(600 \mathrm{MHz}, \mathrm{CDCl}_{3}\right) \delta 8.06(\mathrm{~d}, J=7.9 \mathrm{~Hz}, 2 \mathrm{H}), 7.77(\mathrm{t}, J$ $=7.4 \mathrm{~Hz}, 1 \mathrm{H}), 7.62(\mathrm{~d}, J=7.8 \mathrm{~Hz}, 2 \mathrm{H}), 4.42(\mathrm{t}, J=6.5 \mathrm{~Hz}, 2 \mathrm{H}), 2.37-2.34(\mathrm{~m}, 2 \mathrm{H})$, 1.91-1.84 (m, 2H), 1.68-1.58 (m, 8H). ${ }^{13} \mathrm{C}$ NMR (151 MHz, $\left.\mathrm{CDCl}_{3}\right) \delta 179.6,159.0,138.2$, $135.5,129.6,129.2,128.5,127.8,71.6,33.9,28.8,28.7,28.3,25.4$, 24.5. ESI-MS $[\mathrm{M}+\mathrm{H}]^{+}$ $\mathrm{m} / \mathrm{z}: 385.1$.

4-(2-(Carboxymethoxy)ethoxy)-3-(phenylsulfonyl)-1,2,5-oxadiazole 2-Oxide (4f) -White solid (yield: 85\%). ${ }^{1} \mathrm{H}$ NMR $\left(600 \mathrm{MHz}, \mathrm{CDCl}_{3}\right) \delta 8.07$ (s, 2H), $7.74(\mathrm{~s}, 1 \mathrm{H}), 7.61$ (s, 2H), $4.61(\mathrm{~s}, 2 \mathrm{H}), 4.28(\mathrm{~s}, 2 \mathrm{H}), 4.02(\mathrm{~s}, 2 \mathrm{H}) .{ }^{13} \mathrm{C} \mathrm{NMR}\left(400 \mathrm{MHz}, \mathrm{CDCl}_{3}\right) \delta 173.8$, 154.3, 137.4, 132.6, 132.1, 127.6, 69.8, 67.9, 66.6. ESI-MS $[\mathrm{M}+\mathrm{H}]^{+} \mathrm{m} / z: 345.0$.

4-(2-Carboxy-2-methylpropoxy)-3-(phenylsulfonyl)-1,2,5-oxadiazole 2-Oxide (4g)—White solid (yield: 79\%). ${ }^{1} \mathrm{H}$ NMR $\left(600 \mathrm{MHz}, \mathrm{CDCl}_{3}\right) \delta 8.12-7.95(\mathrm{~m}, 2 \mathrm{H})$, 7.79-7.70 (m, 1H), $7.60(\mathrm{t}, J=7.8 \mathrm{~Hz}, 2 \mathrm{H}), 4.43(\mathrm{~s}, 2 \mathrm{H}), 1.41(\mathrm{~s}, 6 \mathrm{H}) .{ }^{13} \mathrm{C} \mathrm{NMR}(400 \mathrm{MHz}$, $\left.\mathrm{CDCl}_{3}\right) \delta 182.7,153.5,137.4,132.6,132.1,127.6,77.0,43.3,23.4$. ESI-MS $[\mathrm{M}+\mathrm{H}]^{+} \mathrm{m} / z$ : 343.0.

(E)-4-((3-Carboxyallyl)oxy)-3-(phenylsulfonyl)-1,2,5-oxadiazole 2-Oxide (4h)White solid (yield: $88 \%) .{ }^{1} \mathrm{H}$ NMR $\left(600 \mathrm{MHz}, \mathrm{CDCl}_{3}\right) \delta 12.80(\mathrm{~s}, 1 \mathrm{H}), 8.04(\mathrm{~d}, J=8.1 \mathrm{~Hz}$, 2H), $7.90(\mathrm{t}, J=7.4 \mathrm{~Hz}, 1 \mathrm{H}), 7.75(\mathrm{t}, J=7.6 \mathrm{~Hz}, 2 \mathrm{H}), 6.54-6.47(\mathrm{~m}, 1 \mathrm{H}), 5.97(\mathrm{~d}, J=11.6$ $\mathrm{Hz}, 1 \mathrm{H}), 5.48(\mathrm{dd}, J=4.7,2.2 \mathrm{~Hz}, 2 \mathrm{H}) .{ }^{13} \mathrm{C} \mathrm{NMR}\left(400 \mathrm{MHz}, \mathrm{CDCl}_{3}\right) \delta 171.8,155.5,149.5$, 137.4, 132.6, 132.1, 127.6, 119.7, 68.3. ESI-MS $[\mathrm{M}+\mathrm{H}]^{+} \mathrm{m} / z:$ 327.0.

4-(2-(2-(Carboxymethoxy)ethoxy)ethoxy)-3-(phenylsulfonyl)-1,2,5-oxadiazole 2-Oxide (4i)—White solid (yield: 82\%). ${ }^{1} \mathrm{H}$ NMR $\left(600 \mathrm{MHz}, \mathrm{CDCl}_{3}\right) \delta 8.10-8.00$ (m, 2H), 7.98-7.88 (m, 1H), 7.78-7.70 (m, 2H), $4.33(\mathrm{~s}, 2 \mathrm{H}), 4.31(\mathrm{t}, J=7.8 \mathrm{~Hz}, 2 \mathrm{H}), 3.77(\mathrm{t}, J=7.8$ $\mathrm{Hz}, 2 \mathrm{H}), 3.52$ (s, 4H). ${ }^{13} \mathrm{C} \mathrm{NMR}\left(400 \mathrm{MHz}, \mathrm{CDCl}_{3}\right) \delta 173.8,154.3,137.4,132.6,132.1$, 127.6, 70.4, 70.0, 69.7, 67.9, 66.6. ESI-MS $[\mathrm{M}+\mathrm{H}]^{+} \mathrm{m} / \mathrm{z}: 389.1$.

4-(4-Carboxyphenoxy)-3-(phenylsulfonyl)-1,2,5-oxadiazole 2-Oxide (4j)-White solid (yield: 78\%). ${ }^{1} \mathrm{H}$ NMR (600 MHz, $\left.\mathrm{CDCl}_{3}\right) \delta 13.11$ (s, $\left.1 \mathrm{H}\right), 8.05$ (t, $\left.J=8.0 \mathrm{~Hz}, 4 \mathrm{H}\right)$, 
$7.92(\mathrm{t}, J=7.5 \mathrm{~Hz}, 1 \mathrm{H}), 7.77(\mathrm{t}, J=7.9 \mathrm{~Hz}, 2 \mathrm{H}), 7.56(\mathrm{~d}, J=8.8 \mathrm{~Hz}, 2 \mathrm{H}) .{ }^{13} \mathrm{C}$ NMR $(400$ $\left.\mathrm{MHz}, \mathrm{CDCl}_{3}\right) \delta 168.8,157.7,155.3,137.4,132.6,132.1,129.9,127.6,126.7,120.3$. ESI$\mathrm{MS}[\mathrm{M}+\mathrm{H}]^{+} \mathrm{m} / z: 363.0$.

4-(3-Carboxyphenoxy)-3-(phenylsulfonyl)-1,2,5-oxadiazole 2-Oxide (4k)-White solid (yield: 81\%). ${ }^{1} \mathrm{H}$ NMR (600 MHz, $\left.\mathrm{CDCl}_{3}\right) \delta 13.34(\mathrm{~s}, 1 \mathrm{H}), 8.07(\mathrm{~d}, J=7.8 \mathrm{~Hz}, 2 \mathrm{H})$, 7.99 (s, 1H), 7.92 (t, $J=7.4 \mathrm{~Hz}, 2 \mathrm{H}), 7.77(\mathrm{t}, J=7.8 \mathrm{~Hz}, 2 \mathrm{H}), 7.73-7.69(\mathrm{~m}, 1 \mathrm{H}), 7.64(\mathrm{t}, J=$ $7.9 \mathrm{~Hz}, 1 \mathrm{H}) .{ }^{13} \mathrm{C}$ NMR $\left(400 \mathrm{MHz}, \mathrm{CDCl}_{3}\right) \delta 168.01,155.3,152.2,137.4,132.6,132.1$, 130.0, 128.5, 127.6, 126.4, 126.3, 122.3. ESI-MS $[\mathrm{M}+\mathrm{H}]^{+} \mathrm{m} / \mathrm{z}: 363.0$.

4-(4-Carboxy-2-methoxyphenoxy)-3-(phenylsulfonyl)-1,2,5-oxadiazole 2-Oxide (4I)—White solid (yield: 73\%). ${ }^{1} \mathrm{H}$ NMR $\left(600 \mathrm{MHz}, \mathrm{CDCl}_{3}\right) \delta 13.20$ (s, 1H), 8.08 (d, $J=$ $7.6 \mathrm{~Hz}, 2 \mathrm{H}), 7.95$ (t, $J=7.5 \mathrm{~Hz}, 1 \mathrm{H}), 7.81(\mathrm{t}, J=7.9 \mathrm{~Hz}, 2 \mathrm{H}), 7.69$ (d, $J=1.4 \mathrm{~Hz}, 1 \mathrm{H}), 7.64$ $(\mathrm{dd}, J=8.4,1.6 \mathrm{~Hz}, 1 \mathrm{H}), 7.57$ (d, $J=8.3 \mathrm{~Hz}, 1 \mathrm{H}), 3.75$ (s, 3H). ${ }^{13} \mathrm{C}$ NMR $(400 \mathrm{MHz}$, $\left.\mathrm{CDCl}_{3}\right) \delta 168.1,156.2,149.0,146.8,137.4,132.6,132.1,127.6,125.1,122.2,121.9,117.6$, 56.8. ESI-MS $[\mathrm{M}+\mathrm{H}]^{+} \mathrm{m} / \mathrm{z}: 393.0$.

\section{4-(4-(Carboxymethyl)phenoxy)-3-(phenylsulfonyl)-1,2,5-oxadiazole 2-Oxide} (4m)—Colorless oil (yield: 88\%). ${ }^{1} \mathrm{H}$ NMR $\left(600 \mathrm{MHz}, \mathrm{CDCl}_{3}\right) \delta 12.33(\mathrm{~s}, 1 \mathrm{H}), 8.04(\mathrm{~d}, J=$ $7.8 \mathrm{~Hz}, 2 \mathrm{H}), 7.92$ (t, $J=7.4 \mathrm{~Hz}, 1 \mathrm{H}), 7.77$ (t, $J=7.7 \mathrm{~Hz}, 2 \mathrm{H}), 7.37$ (q, $J=8.8 \mathrm{~Hz}, 4 \mathrm{H}$ ), 3.64 (s, 2H). ${ }^{13} \mathrm{C} \mathrm{NMR}\left(400 \mathrm{MHz}, \mathrm{CDCl}_{3}\right) \delta 174.9,155.3,147.0,137.4,132.6,132.1,131.1$, 127.6, 126.6, 118.9, 44.4. ESI-MS [M + H] ${ }^{+} m / z: 376.0$.

4-((2-Carboxy-2-methylpentyl)oxy)-3-(phenylsulfonyl)-1,2,5-oxadiazole 2-Oxide (4n)—Colorless oil (yield: 86\%). ${ }^{1} \mathrm{H}$ NMR $\left(600 \mathrm{MHz}, \mathrm{CDCl}_{3}\right) \delta 8.07(\mathrm{~d}, J=8.9 \mathrm{~Hz}, 2 \mathrm{H})$, $7.93(\mathrm{t}, J=7.5 \mathrm{~Hz}, 1 \mathrm{H}), 7.75(\mathrm{t}, J=7.4 \mathrm{~Hz}, 2 \mathrm{H}), 4.85(\mathrm{dd}, J=283.1,12.4 \mathrm{~Hz}, 2 \mathrm{H}), 1.67$ (dt, $J=98.5,7.7 \mathrm{~Hz}, 2 \mathrm{H}), 1.46-1.36(\mathrm{~m}, 2 \mathrm{H}), 0.97(\mathrm{~s}, 3 \mathrm{H}), 0.89(\mathrm{t}, J=6.6 \mathrm{~Hz}, 3 \mathrm{H}) .{ }^{13} \mathrm{C} \mathrm{NMR}$ $\left(400 \mathrm{MHz}, \mathrm{CDCl}_{3}\right) \delta 179.7,153.5,137.4,132.6,132.1,127.6,73.5,44.8,40.1,26.4,17.2$, 14.7. ESI-MS $[\mathrm{M}+\mathrm{H}]^{+} \mathrm{m} / z: 370.1$.

\section{The Preparation of Compound 6 (4-(4-Formylphenoxy)-3-} (phenylsulfonyl)-1,2,5-oxadiazole 2-Oxide)-To a stirred suspension of PCC (648 $\mathrm{mg}, 3 \mathrm{mmol}$ ) in DCM at $0{ }^{\circ} \mathrm{C}$ was added compound $3 \mathrm{j}(600 \mathrm{mg}, 1.8 \mathrm{mmol})$, and the solution was stirred at $0{ }^{\circ} \mathrm{C}$ for $5 \mathrm{~h}$. The solution was concentrated under vacuum at room temperature. The residue was extracted with EtOAc three times $(3 \times 50 \mathrm{~mL})$ and washed twice with water and brine. The combined organic layers were dried by anhydrous $\mathrm{Na}_{2} \mathrm{SO}_{4}$ and evaporated under vacuum to give a residue that was purified by silica-gel column chromatography $(\mathrm{P} / \mathrm{E}=3: 1)$ to obtain the product as a white solid (yield: $68 \%) .{ }^{1} \mathrm{H}$ NMR $\left(600 \mathrm{MHz}, \mathrm{DMSO}-d_{6}\right)^{20} \delta 9.98(\mathrm{~s}, 1 \mathrm{H}), 7.95(\mathrm{~d}, J=8.5 \mathrm{~Hz}, 2 \mathrm{H}), 7.91(\mathrm{~d}, J=7.7 \mathrm{~Hz}, 2 \mathrm{H})$, $7.85(\mathrm{t}, J=7.5 \mathrm{~Hz}, 1 \mathrm{H}), 7.70$ (t, $J=7.9 \mathrm{~Hz}, 2 \mathrm{H}), 7.29$ (d, $J=8.5 \mathrm{~Hz}, 2 \mathrm{H})$.

The Preparation of Compound 7 ((E)-4-(4-(2-Carboxyvinyl)-phenoxy)-3(phenylsulfonyl)-1,2,5-oxadiazole 2-Oxide)-To a solution of propandioic acid (710 $\mathrm{mg}, 2.4 \mathrm{mmol})$ in pyridine was added pyrrolidine $(0.03 \mathrm{~mL})$, and the mixture was stirred at room temperature for $20 \mathrm{~min}$. After that, the compound 6 (750 mg, $2.4 \mathrm{mmol})$ was added, and the reaction mixture was heated at $100{ }^{\circ} \mathrm{C}$ in reflux for $3 \mathrm{~h}$. Pyridine was removed, and 
the residue was extracted with EtOAc $(3 \times 50 \mathrm{~mL})$ and washed twice with water and brine. The organic portion was dried by anhydrous $\mathrm{Na}_{2} \mathrm{SO}_{4}$. The crude product was obtained by removing EtOAc and purified by silica chromatography column $(\mathrm{P} / \mathrm{E}=3: 1)$ to obtain the product as white solid (yield: 80\%). ${ }^{1} \mathrm{H}$ NMR $\left(600 \mathrm{MHz}, \mathrm{DMSO}-d_{6}\right) \delta 12.47(\mathrm{~s}, 1 \mathrm{H}), 8.05$ (d, $J=7.8 \mathrm{~Hz}, 2 \mathrm{H}), 7.93(\mathrm{t}, J=7.4 \mathrm{~Hz}, 1 \mathrm{H}), 7.83(\mathrm{~d}, J=8.7 \mathrm{~Hz}, 2 \mathrm{H}), 7.77(\mathrm{t}, J=7.8 \mathrm{~Hz}$, 2H), $7.63(\mathrm{~d}, J=16.0 \mathrm{~Hz}, 1 \mathrm{H}), 7.48(\mathrm{~d}, J=8.7 \mathrm{~Hz}, 2 \mathrm{H}), 6.57(\mathrm{~d}, J=16.0 \mathrm{~Hz}, 1 \mathrm{H}) .{ }^{13} \mathrm{C}$ NMR (400 MHz, DMSO- $\left.d_{6}\right) \delta 170.5,155.3,153.2,143.7,137.4,132.6,132.1,131.9,130.9$, 127.6, 121.7, 115.0. ESI-MS [M + H] $]^{+} m / z:$ 389.0.

\section{General Procedure for the Preparation of Compounds 5a-5o}

\section{4-(4-(Hydroxyamino)-4-oxobutoxy)-3-(phenylsulfonyl)-1,2,5-oxadiazole 2-}

Oxide (5a)-To a solution of compound $4 \mathbf{a}(1.2 \mathrm{~g}, 3.8 \mathrm{mmol})$ in dried THF was added isobutyl chlorocarbonate $(0.9 \mathrm{~mL}, 3.9 \mathrm{mmol})$ dropwise at $0{ }^{\circ} \mathrm{C}$; after stirring for $0.5 \mathrm{~h}$, triethylamine $(0.9 \mathrm{~mL}, 2.5 \mathrm{mmol})$ was added dropwise at $0{ }^{\circ} \mathrm{C}$. The mixture was further stirred for an additional $1 \mathrm{~h}$ at room temperature, and solid precipitates were filtered, resulting in the first filtrate. Potassium hydroxide $(319.2 \mathrm{mg}, 5.7 \mathrm{mmol})$ and hydroxylamine hydrochloride (396.1 mg, $5.7 \mathrm{mmol}$ ) were dissolved in anhydrous menthol completely, and the residue was filtered to obtain the second filtrate. The first filtrate was added into the second filtrate, and the mixture was stirred for an additional $4 \mathrm{~h}$ at room temperature under a nitrogen atmosphere. Ferric trichloride was the color-producing reagent. THF and menthol were removed after the $\mathrm{pH}$ of the reacted solution was adjusted to 3.0 with $2 \mathrm{~N} \mathrm{HCl}$. Then, the residue was extracted with EtOAc. The organic portion was dried by anhydrous $\mathrm{Na}_{2} \mathrm{SO}_{4}$. The crude product was obtained by removing EtOAc and purified by silica chromatography column $(\mathrm{P} / \mathrm{E}=3: 1)$ to obatin the product as a white solid (yield: $73 \%) . \mathrm{mp} 139-141{ }^{\circ} \mathrm{C} .{ }^{1} \mathrm{H}$ NMR (600 MHz, DMSO- $\left.d_{6}\right) \delta 10.51(\mathrm{~s}, 1 \mathrm{H}), 8.80(\mathrm{~s}, 1 \mathrm{H}), 8.03(\mathrm{~d}, J=8.2 \mathrm{~Hz}, 2 \mathrm{H}), 7.89(\mathrm{t}$, $J=7.4 \mathrm{~Hz}, 1 \mathrm{H}), 7.74(\mathrm{t}, J=7.5 \mathrm{~Hz}, 2 \mathrm{H}), 4.40(\mathrm{t}, J=6.2 \mathrm{~Hz}, 2 \mathrm{H}), 2.13(\mathrm{t}, J=7.3 \mathrm{~Hz}, 2 \mathrm{H})$, 2.02-1.97 (m, 2H). ${ }^{13} \mathrm{C}$ NMR (400 MHz, DMSO- $\left.d_{6}\right) \delta 168.4,159.1,137.3,136.4,130.2$, 128.6, 128.5, 110.7, 71.0, 28.3, 24.4. HRMS (ESI) $\mathrm{m} / z$ calcd for $\mathrm{C}_{12} \mathrm{H}_{14} \mathrm{~N}_{3} \mathrm{O}_{7} \mathrm{~S}[\mathrm{M}+\mathrm{H}]^{+}$, 344.0547; found, 344.0548 .

4-((5-(Hydroxyamino)-5-oxopentyl)oxy)-3-(phenylsulfonyl)-1,2,5-oxadiazole 2Oxide (5b)—White solid (yield: 68\%). mp 119-121 ${ }^{\circ} \mathrm{C} .{ }^{1} \mathrm{H}$ NMR (600 MHz, DMSO- $\left.d_{6}\right) \delta$ 10.39 (s, 1H), 8.74 (s, 1H), 8.02 (d, $J=7.9 \mathrm{~Hz}, 2 \mathrm{H}), 7.90$ (t, $J=7.3 \mathrm{~Hz}, 1 \mathrm{H}), 7.76$ (t, $J=7.8$ $\mathrm{Hz}, 2 \mathrm{H}), 4.38(\mathrm{t}, J=6.1 \mathrm{~Hz}, 2 \mathrm{H}), 1.79-1.71(\mathrm{~m}, 2 \mathrm{H}), 1.66-1.58(\mathrm{~m}, 3 \mathrm{H}), 1.53(\mathrm{t}, J=6.8 \mathrm{~Hz}$, $2 \mathrm{H}) .{ }^{13} \mathrm{C}$ NMR (400 MHz, DMSO- $\left.d_{6}\right) \delta 169.2,159.3,137.6,136.6,130.6,128.8,110.9$, 71.5,32.1, 27.9, 21. 8. HRMS (ESI) $\mathrm{m} / z$ calcd for $\mathrm{C}_{13} \mathrm{H}_{16} \mathrm{~N}_{3} \mathrm{O}_{7} \mathrm{~S}[\mathrm{M}+\mathrm{H}]^{+}, 358.0703$; found, 358.0705 .

\section{4-((6-(Hydroxyamino)-6-oxohexyl)oxy)-3-(phenylsulfonyl)-1,2,5-oxadiazole 2-} Oxide (5c)—White solid (yield: $62 \%$ ). mp $135-137{ }^{\circ} \mathrm{C} .{ }^{1} \mathrm{H}$ NMR (600 MHz, DMSO- $\left.d_{6}\right) \delta$ $10.37(\mathrm{~s}, 1 \mathrm{H}), 8.70(\mathrm{~s}, 1 \mathrm{H}), 8.04-7.99(\mathrm{~m}, 2 \mathrm{H}), 7.90(\mathrm{t}, J=7.5 \mathrm{~Hz}, 1 \mathrm{H}), 7.76(\mathrm{t}, J=7.9 \mathrm{~Hz}$, $2 \mathrm{H}), 4.37(\mathrm{t}, J=6.3 \mathrm{~Hz}, 2 \mathrm{H}), 1.97(\mathrm{t}, J=7.4 \mathrm{~Hz}, 2 \mathrm{H}), 1.78-1.69(\mathrm{~m}, 2 \mathrm{H}), 1.57-1.51(\mathrm{~m}, 2 \mathrm{H})$, $1.32(\mathrm{dt}, J=15.3,7.7 \mathrm{~Hz}, 2 \mathrm{H}) .{ }^{13} \mathrm{C}$ NMR $\left(400 \mathrm{MHz}\right.$, DMSO- $\left.d_{6}\right) \delta 169.4,159.3,137.6$, 136.6, 130.5, 128.8, 110.9, 71.8, 32.6, 28.1, 25.2, 25.1. HRMS (ESI) $\mathrm{m} / \mathrm{z}$ calcd for $\mathrm{C}_{14} \mathrm{H}_{18} \mathrm{~N}_{3} \mathrm{O}_{7} \mathrm{~S}[\mathrm{M}+\mathrm{H}]^{+}, 372.0860$; found, 372.0866 . 
4-((7-(Hydroxyamino)-7-oxoheptyl)oxy)-3-(phenylsulfonyl)-1,2,5-oxadiazole 2Oxide (5d)—White solid (yield: 70\%). ${ }^{1} \mathrm{H}$ NMR (600 MHz, DMSO- $\left.d_{6}\right) \delta 10.35$ (s, 1H), $8.62(\mathrm{~s}, 1 \mathrm{H}), 8.01(\mathrm{~d}, J=7.4 \mathrm{~Hz}, 2 \mathrm{H}), 7.91(\mathrm{~s}, 1 \mathrm{H}), 7.76(\mathrm{t}, J=7.9 \mathrm{~Hz}, 2 \mathrm{H}), 4.38(\mathrm{t}, J=6.3$ $\mathrm{Hz}, 2 \mathrm{H}), 1.97$ (t, $J=7.4 \mathrm{~Hz}, 2 \mathrm{H}), 1.78-1.69(\mathrm{~m}, 2 \mathrm{H}), 1.54-1.49(\mathrm{~m}, 2 \mathrm{H}), 1.36-1.25(\mathrm{~m}$, $4 \mathrm{H}) .{ }^{13} \mathrm{C}$ NMR (151 MHz, DMSO- $\left.d_{6}\right) \delta 169.6,159.3,136.6,130.5,130.2,128.7,127.9$, $110.9,71.9,32.7,28.5,28.2,25.5,25.2$, HRMS (ESI) $m / z$ calcd for $\mathrm{C}_{15} \mathrm{H}_{20} \mathrm{~N}_{3} \mathrm{O}_{7} \mathrm{~S}[\mathrm{M}+$ $\mathrm{H}]^{+}, 386.1016$; found, 386.1032 .

4-((8-(Hydroxyamino)-8-oxooctyl)oxy)-3-(phenylsulfonyl)-1,2,5-oxadiazole 2Oxide (5e)—White solid (yield: 64\%). ${ }^{1} \mathrm{H}$ NMR (600 MHz, DMSO- $\left.d_{6}\right) \delta 10.34$ (s, 1H), $8.66(\mathrm{~s}, 1 \mathrm{H}), 8.01(\mathrm{~d}, J=7.5 \mathrm{~Hz}, 2 \mathrm{H}), 7.91(\mathrm{t}, J=7.4 \mathrm{~Hz}, 1 \mathrm{H}), 7.76(\mathrm{t}, J=7.9 \mathrm{~Hz}, 2 \mathrm{H}), 4.38$ $(\mathrm{t}, J=6.3 \mathrm{~Hz}, 2 \mathrm{H}), 1.96(\mathrm{t}, J=7.3 \mathrm{~Hz}, 2 \mathrm{H}), 1.73(\mathrm{dd}, J=13.5,6.4 \mathrm{~Hz}, 2 \mathrm{H}), 1.51(\mathrm{dt}, J=$ 14.5, 7.4 Hz, 2H), 1.35-1.21 (m, 6H). ${ }^{13} \mathrm{C}$ NMR (151 MHz, DMSO) $\delta 169.6,159.3,137.8$, 136.6, 130.5, 128.7, 110.9, 72.0, 32.7, 28.9, 28.7, 28.3, 25.5, 25.4. HRMS (ESI) $\mathrm{m} / \mathrm{z}$ calcd for $\mathrm{C}_{16} \mathrm{H}_{22} \mathrm{~N}_{3} \mathrm{O}_{7} \mathrm{~S}[\mathrm{M}+\mathrm{H}]^{+}, 400.1173$; found, 400.1172 .

4-(2-(2-(Hydroxyamino)-2-oxoethoxy)ethoxy)-3-(phenylsulfonyl)-1,2,5oxadiazole 2-Oxide (5f)—White solid (yield: 66\%). mp 143-145 ${ }^{\circ} \mathrm{C} .{ }^{1} \mathrm{H}$ NMR (600 MHz, DMSO- $\left.d_{6}\right) \delta 10.54(\mathrm{~s}, 1 \mathrm{H}), 8.89(\mathrm{~s}, 1 \mathrm{H}), 8.03(\mathrm{~d}, J=7.5 \mathrm{~Hz}, 2 \mathrm{H}), 7.90(\mathrm{t}, J=7.5 \mathrm{~Hz}$, $1 \mathrm{H}), 7.75(\mathrm{t}, J=7.9 \mathrm{~Hz}, 2 \mathrm{H}), 4.58-4.49(\mathrm{~m}, 2 \mathrm{H}), 3.97(\mathrm{~s}, 2 \mathrm{H}), 3.86-3.80(\mathrm{~m}, 2 \mathrm{H}) .{ }^{13} \mathrm{C}$ NMR $\left(400 \mathrm{MHz}, \mathrm{DMSO}-d_{6}\right) \delta 171.0,158.8,137.2,136.0,129.9,128.2,110.4,72.1,70.6,68.9$, 68.2, 42.8. HRMS (ESI) $\mathrm{m} / z$ calcd for $\mathrm{C}_{12} \mathrm{H}_{14} \mathrm{~N}_{3} \mathrm{O}_{8} \mathrm{~S}[\mathrm{M}+\mathrm{H}]^{+}$, 360.0496; found, 360.0497 .

4-(3-(Hydroxyamino)-2,2-dimethyl-3-oxopropoxy)-3-(phenylsulfonyl)-1,2,5oxadiazole 2-Oxide (5g)—White solid (yield: 71\%). mp 128-130 ${ }^{\circ} \mathrm{C} .{ }^{1} \mathrm{H}$ NMR (600 MHz, DMSO- $\left.d_{6}\right) \delta 10.61(\mathrm{~s}, 1 \mathrm{H}), 8.81(\mathrm{~s}, 1 \mathrm{H}), 7.99(\mathrm{~d}, J=7.5 \mathrm{~Hz}, 2 \mathrm{H}), 7.90(\mathrm{t}, J=6.8 \mathrm{~Hz}$, $1 \mathrm{H}), 7.76(\mathrm{t}, J=7.4 \mathrm{~Hz}, 2 \mathrm{H}), 4.38(\mathrm{~s}, 2 \mathrm{H}), 1.22(\mathrm{~s}, 6 \mathrm{H}) .{ }^{13} \mathrm{C} \mathrm{NMR}$ (400 MHz, DMSO- $\left.d_{6}\right) \delta$ 171.4, 159.3, 137.9, 136.5, 130.6, 130.6, 128.62, 110.7, 76.99, 41.7, 22.2. HRMS (ESI) $\mathrm{m} / \mathrm{z}$ calcd for $\mathrm{C}_{13} \mathrm{H}_{16} \mathrm{~N}_{3} \mathrm{O}_{7} \mathrm{~S}[\mathrm{M}+\mathrm{H}]^{+}$, 358.0704; found, 358.0703.

(E)-4-((4-(Hydroxyamino)-4-oxobut-2-en-1-yl)oxy)-3-(phenylsulfonyl)-1,2,5oxadiazole 2-Oxide (5h)-White solid (yield: 76\%). mp 144-146 ${ }^{\circ} \mathrm{C} .{ }^{1} \mathrm{H}$ NMR (600 MHz, DMSO- $\left.d_{6}\right) \delta 8.10(\mathrm{~d}, J=7.5 \mathrm{~Hz}, 2 \mathrm{H}), 7.86(\mathrm{t}, J=7.5 \mathrm{~Hz}, 1 \mathrm{H}), 7.73(\mathrm{t}, J=7.9 \mathrm{~Hz}$, $2 \mathrm{H}), 6.96(\mathrm{dt}, J=15.3,4.3 \mathrm{~Hz}, 1 \mathrm{H}), 6.27(\mathrm{~d}, J=15.5 \mathrm{~Hz}, 1 \mathrm{H}), 5.15(\mathrm{~d}, J=3.1 \mathrm{~Hz}, 2 \mathrm{H}) .{ }^{13} \mathrm{C}$ NMR (400 MHz, DMSO- $\left.d_{6}\right) \delta 161.2,158.6,139.1,136.0,129.9,128.2,120.4,76.7,69.0$. HRMS (ESI) $\mathrm{m} / z$ calcd for $\mathrm{C}_{12} \mathrm{H}_{12} \mathrm{~N}_{3} \mathrm{O}_{7} \mathrm{~S}[\mathrm{M}+\mathrm{H}]^{+}, 342.0390$; found, 342.0393 .

4-(2-(2-(2-(Hydroxyamino)-2-oxoethoxy)ethoxy)ethoxy)-3(phenylsulfonyl)-1,2,5-oxadiazole 2-Oxide (5i)—White solid (yield: 70\%). mp 139-141 ${ }^{\circ} \mathrm{C} .{ }^{1} \mathrm{H}$ NMR (600 MHz, DMSO- $\left.d_{6}\right) \delta 10.40(\mathrm{~s}, 1 \mathrm{H}), 8.77(\mathrm{~s}, 1 \mathrm{H}), 8.03(\mathrm{~d}, J=7.8$ $\mathrm{Hz}, 2 \mathrm{H}), 7.91(\mathrm{t}, J=7.4 \mathrm{~Hz}, 1 \mathrm{H}), 7.76(\mathrm{t}, J=7.3 \mathrm{~Hz}, 2 \mathrm{H}), 4.54-4.50(\mathrm{~m}, 2 \mathrm{H}), 3.89(\mathrm{~s}, 2 \mathrm{H})$, 3.84-3.80 (m, 2H), $3.65(\mathrm{~d}, J=3.0 \mathrm{~Hz}, 2 \mathrm{H}), 3.61(\mathrm{~d}, J=3.2 \mathrm{~Hz}, 2 \mathrm{H}) .{ }^{13} \mathrm{C} \mathrm{NMR}(400 \mathrm{MHz}$, DMSO- $\left.d_{6}\right) \delta 165.5,158.8,137.2,136.0,129.9,128.1,70.8,70.2,69.62,68.9,67.7$. HRMS (ESI) $\mathrm{m} / z$ calcd for $\mathrm{C}_{17} \mathrm{H}_{14} \mathrm{~N}_{3} \mathrm{O}_{7} \mathrm{~S}[\mathrm{M}+\mathrm{H}]^{+}, 404.0547$; found, 404.0549 . 
4-(4-(Hydroxycarbamoyl)phenoxy)-3-(phenylsulfonyl)-1,2,5-oxadiazole 2-Oxide (5j)—White solid (yield: 78\%). mp 171-172 ${ }^{\circ} \mathrm{C} .{ }^{1} \mathrm{H}$ NMR (600 MHz, DMSO- $d_{6}$ ) $\delta 11.29$ (s, $1 \mathrm{H}), 9.10(\mathrm{~s}, 1 \mathrm{H}), 8.04(\mathrm{~d}, J=7.3 \mathrm{~Hz}, 2 \mathrm{H}), 7.93(\mathrm{t}, J=6.8 \mathrm{~Hz}, 1 \mathrm{H}), 7.87(\mathrm{~d}, J=7.9 \mathrm{~Hz}, 2 \mathrm{H})$, 7.77 (t, $J=7.4 \mathrm{~Hz}, 2 \mathrm{H}), 7.52(\mathrm{~d}, J=8.0 \mathrm{~Hz}, 2 \mathrm{H}) .{ }^{13} \mathrm{C}$ NMR $\left(400 \mathrm{MHz}\right.$, DMSO- $\left.d_{6}\right) \delta 163.6$, $158.5,155.1,137.3,136.8,131.4,130.5,129.5,129.1,119.9,111.8$. HRMS (ESI) $\mathrm{m} / z$ calcd for $\mathrm{C}_{15} \mathrm{H}_{12} \mathrm{~N}_{3} \mathrm{O}_{7} \mathrm{~S}[\mathrm{M}+\mathrm{H}]^{+}, 378.0390$; found, 378.0439.

4-(3-(Hydroxycarbamoyl)phenoxy)-3-(phenylsulfonyl)-1,2,5-oxadiazole 2-Oxide (5k)—White solid (yield: 64\%). mp 177-179 ${ }^{\circ} \mathrm{C} .{ }^{1} \mathrm{H}$ NMR (600 MHz, DMSO- $d_{6}$ ) $\delta 11.31$ (s, 1H), $9.16(\mathrm{~s}, 1 \mathrm{H}), 8.04(\mathrm{~d}, J=7.6 \mathrm{~Hz}, 2 \mathrm{H}), 7.92(\mathrm{~d}, J=7.4 \mathrm{~Hz}, 1 \mathrm{H}), 7.78-7.72(\mathrm{~m}, 4 \mathrm{H})$, 7.62-7.57 (m, 2H). ${ }^{13} \mathrm{C}$ NMR (400 MHz, DMSO- $\left.d_{6}\right) \delta 167.3,157.6,144.0,135.4,129.8$, 119.0, 118.9, 117.3, 114.4. HRMS (ESI) $m / z$ calcd for $\mathrm{C}_{15} \mathrm{H}_{12} \mathrm{~N}_{3} \mathrm{O}_{7} \mathrm{~S}[\mathrm{M}+\mathrm{H}]^{+}, 378.0390$; found, 378.0378 .

4-(4-(Hydroxycarbamoyl)-2-methoxyphenoxy)-3-(phenylsulfonyl)-1,2,5oxadiazole 2-Oxide (5I)—White solid (yield: 72\%). mp 198-200 ${ }^{\circ} \mathrm{C} .{ }^{1} \mathrm{H}$ NMR (600 MHz, DMSO- $\left.d_{6}\right) \delta 11.26(\mathrm{~s}, 1 \mathrm{H}), 9.07(\mathrm{~s}, 1 \mathrm{H}), 8.09$ (d, $\left.J=7.8 \mathrm{~Hz}, 2 \mathrm{H}\right), 7.95(\mathrm{t}, J=7.4 \mathrm{~Hz}$, $1 \mathrm{H}), 7.81(\mathrm{t}, J=7.6 \mathrm{~Hz}, 2 \mathrm{H}), 7.57(\mathrm{~s}, 1 \mathrm{H}), 7.52(\mathrm{~d}, J=8.2 \mathrm{~Hz}, 1 \mathrm{H}), 7.44(\mathrm{~d}, J=8.5 \mathrm{~Hz}, 1 \mathrm{H})$, 3.79 (s, 3H). ${ }^{13} \mathrm{C}$ NMR (400 MHz, DMSO- $\left.d_{6}\right) \delta 163.0,158.4,149.4,142.8,137.0,136.4$, $130.2,128.4,121.6,119.8,112.1,110.8,56.3$. HRMS (ESI) $\mathrm{m} / z$ calcd for $\mathrm{C}_{16} \mathrm{H}_{14} \mathrm{~N}_{3} \mathrm{O}_{8} \mathrm{~S}[\mathrm{M}$ $+\mathrm{H}]^{+}, 408.0496$; found, 408.0500 .

4-(4-(2-(Hydroxyamino)-2-oxoethyl)phenoxy)-3-(phenylsulfonyl)-1,2,5oxadiazole 2-Oxide (5m)—White solid (yield: $73 \%)$. ${ }^{1} \mathrm{H}$ NMR (600 MHz, DMSO- $\left.d_{6}\right) \delta$ $10.62(\mathrm{~s}, 1 \mathrm{H}), 8.79$ (s, 1H), 8.04 (d, $J=7.8 \mathrm{~Hz}, 2 \mathrm{H}), 7.92$ (t, $J=7.4 \mathrm{~Hz}, 1 \mathrm{H}), 7.77$ (t, $J=7.6$ $\mathrm{Hz}, 2 \mathrm{H}), 7.35$ (dd, $J=17.3,8.6 \mathrm{~Hz}, 4 \mathrm{H}), 3.34$ (s, $2 \mathrm{H}) .{ }^{13} \mathrm{C}$ NMR (400 MHz, DMSO- $d_{6}$ ) $\delta$ $158.3,136.9,136.1,131.3,130.4,129.9,129.5,128.5,128.3,119.3,29.9$. HRMS (ESI) $\mathrm{m} / \mathrm{z}$ calcd for $\mathrm{C}_{16} \mathrm{H}_{14} \mathrm{~N}_{3} \mathrm{O}_{7} \mathrm{~S}[\mathrm{M}+\mathrm{H}]^{+}, 392.0547$; found, 392.0550.

4-((2-(Hydroxycarbamoyl)-2-methylpentyl)oxy)-3-(phenylsulfonyl)-1,2,5oxadiazole 2-Oxide (5n)—White solid (yield: $54 \%) .{ }^{1} \mathrm{H}$ NMR (600 MHz, DMSO- $\left.d_{6}\right) \delta$ $10.63(\mathrm{~s}, 1 \mathrm{H}), 8.79(\mathrm{~s}, 1 \mathrm{H}), 8.04(\mathrm{~d}, J=7.5 \mathrm{~Hz}, 2 \mathrm{H}), 7.92(\mathrm{t}, J=7.5 \mathrm{~Hz}, 1 \mathrm{H}), 7.77(\mathrm{t}, J=7.7$ $\mathrm{Hz}, 2 \mathrm{H}), 7.35$ (dd, $J=17.9,8.4 \mathrm{~Hz}, 4 \mathrm{H}), 3.34(\mathrm{~s}, 2 \mathrm{H}) .{ }^{13} \mathrm{C}$ NMR (400 MHz, DMSO- $d_{6}$ ) 177.2, 172.4, 131.3, 129.96, 129.5, 128.5, 67.0, 64.9, 47.2, 36.3, 35.7, 19.8, 17.7, 13.7. HRMS (ESI) $m / z$ calcd for $\mathrm{C}_{15} \mathrm{H}_{20} \mathrm{~N}_{3} \mathrm{O}_{7} \mathrm{~S}[\mathrm{M}+\mathrm{H}]^{+}, 386.1016$; found, 386.1017 .

(E)-4-(4-(3-(Hydroxyamino)-3-oxoprop-1-en-1-yl)phenoxy)-3(phenylsulfonyl)-1,2,5-oxadiazole 2-Oxide (5o)-White solid (yield: 69\%). mp 153-155 ${ }^{\circ} \mathrm{C} .{ }^{1} \mathrm{H}$ NMR (600 MHz, DMSO- $d_{6}$ ) $\delta 10.79$ (s, $1 \mathrm{H}$ ), 9.08 (s, 1H), 7.91 (d, $J=8.5$ $\mathrm{Hz}, 1 \mathrm{H}), 7.76(\mathrm{dd}, J=25.3,7.9 \mathrm{~Hz}, 2 \mathrm{H}), 7.63(\mathrm{~d}, J=8.4 \mathrm{~Hz}, 2 \mathrm{H}), 7.47(\mathrm{~d}, J=15.9 \mathrm{~Hz}, 1 \mathrm{H})$, $7.34(\mathrm{dd}, J=15.9,8.4 \mathrm{~Hz}, 2 \mathrm{H}), 7.29(\mathrm{~d}, J=8.5 \mathrm{~Hz}, 2 \mathrm{H}), 6.44(\mathrm{~d}, J=15.8 \mathrm{~Hz}, 1 \mathrm{H}) .{ }^{13} \mathrm{C}$ NMR (400 MHz, DMSO- $\left.d_{6}\right) \delta 163.3,158.7,138.3,129.0,125.8,115.6,115.4$. HRMS (ESI) $m / z$ calcd for $\mathrm{C}_{14} \mathrm{H}_{18} \mathrm{~N}_{3} \mathrm{O}_{9} \mathrm{~S}[\mathrm{M}+\mathrm{H}]^{+}$, 404.0758; found, 404.0755. 


\section{In Vitro HeLa Extracts Inhibition Fluorescence Assay}

In vitro HDAC inhibition assays were conducted as previously described. ${ }^{32}$ In brief, $10 \mu \mathrm{L}$ of HeLa extracts was mixed with various concentrations of $50 \mu \mathrm{L}$ tested compounds $(0.039$, $0.39,1.56,6.25,25,100 \mu \mathrm{M})$ and SAHA as the positive control. Five minutes later, fluorogenic substrate Boc-Lys (acetyl)-AMC ( $40 \mu \mathrm{L})$ was added, and the mixture was incubated at $37^{\circ} \mathrm{C}$ for $30 \mathrm{~min}$ and then stopped by addition of $100 \mu \mathrm{L}$ of developer containing trypsin and TSA. After incubation at $37{ }^{\circ} \mathrm{C}$ for $20 \mathrm{~min}$, fluorescence intensity was measured using a microplate reader at excitation and emission wavelengths of 390 and $460 \mathrm{~nm}$, respectively. The inhibition ratios were calculated from the fluorescence intensity readings of tested wells relative to those of control wells, and the $\mathrm{IC}_{50}$ values were calculated using a regression analysis of the concentration/inhibition data.

\section{In Vitro Antiproliferative Assay}

In vitro antiproliferative assays were determined by the MTT (3-(4,5-dimethylthiazol-2yl)-2,5-diphenyltetrazolium bromide) method as previously described. ${ }^{32}$ Briefly, all cell lines were maintained in RPMI 1640 medium containing $10 \% \mathrm{FBS}$ at $37{ }^{\circ} \mathrm{C}$ in a $5 \% \mathrm{CO}_{2}$ humidified incubator. Cells were passaged the day before dosing into a 96-well cell plate and allowed to grow for a minimum of $4 \mathrm{~h}$ prior to addition of compounds. After addition of the compounds, the plates were incubated for an additional $48 \mathrm{~h}$, and then $0.5 \%$ MTT solution was added to each well. After further incubation for $4 \mathrm{~h}$, the formazan formed from MTT was extracted by adding $200 \mu \mathrm{L}$ of DMSO for $15 \mathrm{~min}$. Absorbance was then determined using an ELISA reader at 490 and $630 \mathrm{~nm}$, and the $\mathrm{IC}_{50}$ values were calculated according to the inhibition ratios.

\section{In Vitro Nitrite Measurement}

The nitrite measurement in vitro was tested using a reported method. ${ }^{34}$ The levels of NO generated by individual compounds in the cells are presented as that of nitrite and were determined by a colorimetric assay using a kit (purchased from Beyotime, China) according to the manufacturer's instructions. Briefly, HEL cells $\left(5 \times 10^{5} /\right.$ well $)$ were treated with a 100 $\mu \mathrm{M}$ test compounds for 3 or $5 \mathrm{~h}$. Subsequently, the cells were harvested, and their cell lysates were prepared and then mixed with Griess reagent for $10 \mathrm{~min}$ at $37^{\circ} \mathrm{C}$, followed by measurement at $540 \mathrm{~nm}$ by an ELISA plate reader. The cells treated with DMSO were used as negative controls for the background levels of nitrite production, whereas sodium nitrite at different concentrations was prepared as the positive control for the standard curve.

\section{In Vitro Antiproliferative Assay with Hemoglobin}

This assay was determined by the MTT (3-(4,5-dimethylthiazol-2-yl)-2,5diphenyltetrazolium bromide) method as described above. Briefly, HEL cells were maintained in RPMI 1640 medium containing $10 \% \mathrm{FBS}$ at $37{ }^{\circ} \mathrm{C}$ in a $5 \% \mathrm{CO}_{2}$ humidified incubator. Cells were passaged the day before dosing into a 96-well cell plate and allowed to grow for a minimum of $4 \mathrm{~h}$ prior to addition of hemoglobin and 5c. HEL cells were pretreated with the indicated concentrations of the NO scavenger hemoglobin $(0,2.5,5,10$, or $20 \mu \mathrm{M}$ ) for $1 \mathrm{~h}$ and treated with $2 \mu \mathrm{M} 5 \mathrm{c}$ for $24 \mathrm{~h}$. After addition of the compounds, the plates were incubated for an additional $48 \mathrm{~h}$, and then $0.5 \%$ MTT solution was added to each 
well. After further incubation for $4 \mathrm{~h}$, the formazan formed from MTT was extracted by adding $200 \mu \mathrm{L}$ of DMSO for $15 \mathrm{~min}$. Absorbance was then determined using an ELISA reader at 490 and $630 \mathrm{~nm}$, and the $\mathrm{IC}_{50}$ values were calculated according to the inhibition ratios.

\section{In Vitro Cell Apoptosis Assay}

HEL $\left(1 \times 10^{5} /\right.$ well $)$ cells were incubated in six-well plates for $24 \mathrm{~h}$ and then treated with $0.1 \%$ DMSO (as control), various doses of SAHA, or $5 \mathrm{c}(0.5,1,2 \mu \mathrm{M})$ in fresh growth medium. After $24 \mathrm{~h}$, the growth medium was collected, and the cells were trypsinized and collected with the corresponding medium. After centrifugation at $2000 \mathrm{rpm}$ at $4{ }^{\circ} \mathrm{C}$ for 5 min, the supernatant was removed completely, and the cells were washed twice with prechilled PBS. A $200 \mu \mathrm{L}$ volume of $1 \times$ binding buffer, $2.5 \mu \mathrm{L}$ of $7-\mathrm{AAD}$, and $2.5 \mu \mathrm{L}$ of propidium iodide were added (PE-Annexin V kit, BD Pharmingen). The cells were gently vortex-mixed and incubated for $15 \mathrm{~min}$ at $25{ }^{\circ} \mathrm{C}$ in the dark. Using cells stained with 7-AAD and propidium iodide alone as the positive control, the samples were detected with a FACS Calibur flow cytometer (Becton Dickinson).

\section{In Vitro Cell Cycle Assay}

HEL cells were seeded into 6-well plates at a density of $4 \times 10^{5}$ per well. After overnight incubation, cells were treated with the same concentration $(0.5 \mu \mathrm{M})$ of $\mathbf{5 c}, \mathbf{2}$, and SAHA. After $48 \mathrm{~h}$ of treatment, cells were harvested and fixed with $70 \%$ ethanol in phosphate buffer overnight. Then, the cells were washed with PBS twice, incubated with DNase-free RNase A ( $1 \mathrm{mg} / \mathrm{mL}$, Solarbio, China) for $30 \mathrm{~min}$, and stained with propidium iodide $(50 \mathrm{mg} / \mathrm{mL}$, Solarbio, China) for $30 \mathrm{~min}$, avoiding light, at room temperature. DNA content was measured by a flow cytometer (FACScan, Becton Dickinson) and analyzed by MODFit LT for Mac, v3.0, software.

\section{In Vivo Antitumor Assay against HEL}

In vivo human tumor xenografts were established as previously described.$^{32}$ In brief, HEL tumor cells were cultured in RPMI 1640 medium containing 10\% FBS and maintained in a $5 \% \mathrm{CO}_{2}$ humidified incubator at $37^{\circ} \mathrm{C}$. For in vivo antitumor assays, the aforementioned cells were inoculated subcutaneously in the right flanks of male athymic nude mice (BALB/ c-nu, 6-8 weeks old, HFK Bioscience Co., LTD, Beijing, China). About 10 days after injection, tumors were palpable (about $100 \mathrm{~mm}^{3}$ ), and mice were randomized into treatment and control groups (6 mice per group). The treatment groups received compound $\mathbf{5 c}$ (120 or $100 \mathrm{mg} / \mathrm{kg} /$ day) or SAHA (120 mg/kg/day) by oral administration, and the blank control group received an equal volume of PBS solution containing DMSO. During treatment, subcutaneous tumors were measured with a vernier caliper every 3 days, and body weight was monitored regularly. After treatment, mice were sacrificed and dissected to weigh the tumor tissues and to examine internal organs.

Tumor growth inhibition (TGI) and relative increment ratio $(T / C)$ were calculated as described previously ${ }^{32}$ at the end of treatment to reveal the antitumor effects in tumor weight and tumor volume, respectively. 
TGI $=$ (the mean tumor weight of control group - the mean tumor weight of treated group)/(the mean tumor weight

Tumor volume ( $V$ ) was estimated using the equation $V=a b^{2} / 2$, where $a$ and $b$ stand for the longest and shortest diameters, respectively. $T / C$ was calculated according to the following formula

$$
\frac{T}{C}=\frac{\text { the mean RTV of treated group }}{\text { the mean RTV of control group }}
$$

RTV, namely, relative tumor volume $=V_{t} / V_{0},\left(V_{t}\right.$ : the tumor volume measured at the end of treatment; $V_{0}$ : the tumor volume measured at the beginning of treatment). All of the obtained data were used to evaluate the antitumor potency and toxicity of compounds. Data were analyzed by Student's two-tailed $t$ test. $p<0.05$ was considered to be statistically significant.

\section{In Vitro HDACs Isoform Selectivity Fluorescence Assay}

This assay was conducted by Shanghai Huawei pharmaceutical Co. Ltd., China. HDAC 1 and 6 enzymes were purchased from Abcam (nos. AB101661 and AB42632). HDAC 2, 3, 4, 8, and 11 enzymes were purchased from SignalChem (nos. H84-30G, H85-30G, H86-31G, $\mathrm{H} 90-30 \mathrm{H}$, and $\mathrm{H} 93-30 \mathrm{G})$. All of the enzymatic reactions were conducted at $37{ }^{\circ} \mathrm{C}$ for 30 min. The $50 \mu \mathrm{L}$ reaction mixture contains $25 \mathrm{mM}$ Tris, $\mathrm{pH} 8.0,1 \mathrm{mM} \mathrm{MgCl}_{2}, 0.1 \mathrm{mg} / \mathrm{mL}$ BSA, $137 \mathrm{mM} \mathrm{NaCl}, 2.7 \mathrm{mM} \mathrm{KCl}, \mathrm{HDAC}$, and the corresponding enzyme substrate (the enzyme substrate of HDAC 1, 2, 3, and 6 is Ac-Leu-GlyLys(Ac)-AMC; the enzyme substrate of HDAC 4, 5, 7, 8, and 9 is Ac-Leu-Gly-Lys(Tfa)-AMC; the enzyme substrate of HDAC 10 is Ac-Arg-His-Lys(Ac)-Lys(Ac)-AMC). The compounds were diluted in 10\% DMSO, and $5 \mu L$ of the dilution was added to a $50 \mu L$ reaction so that the final concentration of DMSO is $1 \%$ in all of reactions. The assay was performed by quantitating the amount of fluorescent product in solution following an enzymatic reaction. Fluorescence is then analyzed with excitation at 350-360 $\mathrm{nm}$ and emission at 450-460 nm using a SpectraMax M5 microtiter plate reader. The $\mathrm{IC}_{50}$ values were calculated using nonlinear regression with normalized dose-response fit using GraphPad Prism software.

\section{Western Blotting Analysis}

MV4-11 AML cells $\left(1 \times 10^{6} /\right.$ well $)$ or HEL $(1 \times 10 /$ well $)$ cells were incubated in 6-well plates overnight and then treated with DMSO (as solvent control) or different concentrations $(0.1,1.0$, and $10 \mu \mathrm{M})$ of $\mathbf{5 c}$. After $3 \mathrm{~h}$, the cells were harvested and washed with PBS (0.1 M, $\mathrm{pH}$ 7.4), centrifuged, and resuspended in cell lysis solution containing $20 \mathrm{mM}$ Tris ( $\mathrm{pH} 7.5$ ), $150 \mathrm{mM} \mathrm{NaCl}, 1 \%$ Triton X-100, and several protein inhibitors, such as sodium pyrophosphate, $\beta$-glycerophosphate, EDTA, $\mathrm{Na}_{3} \mathrm{PO}_{4}$, and leupeptin (Beyotime Biotech., China), for $30 \mathrm{~min}$; then, lysates were centrifuged for $15 \mathrm{~min}$ at $12000 \mathrm{rpm}$ at $4{ }^{\circ} \mathrm{C}$, and the supernatant contained the whole-cell extract. Total protein extracts (20 $\mu \mathrm{g}$ per lane) were separated by $10 \%$ SDS polyacrylamide gel electrophoresis and transferred onto PVDF membranes (cat. no. IPVH00010, Millipore). Membrane was blocked with 5\% S36 milk in 
TBS-T (10 mM Tris [pH 7.4], $150 \mathrm{mM} \mathrm{NaCl}$, and $0.1 \%$ Tween 20) for $1 \mathrm{~h}$ at room temperature and then incubated with a 1:1000 dilution of primary antibody overnight at 4 ${ }^{\circ} \mathrm{C}$. Then, the membrane was washed for $10 \mathrm{~min}(\times 3)$ and incubated at a 1:2000 dilution with anti-rabbit goat-HRP-conjugated secondary antibodies for $1.5 \mathrm{~h}$ at room temperature. Finally, the membrane was washed for another $10 \mathrm{~min}(\times 3)$ and developed by enhanced chemiluminescence (ECL, cat. no. WBKLS0050, Mllipore).

\section{Supplementary Material}

Refer to Web version on PubMed Central for supplementary material.

\section{ACKNOWLEDGMENTS}

This work was supported by National High-tech R\&D Program of China, the 863 Program (grant no. 2014AA020523), the National Natural Science Foundation of China (grant nos. 21302111, 81373282, and 21172134), China Postdoctoral Science Foundation funded project (grant nos. 2013M540558 and 2014T70654), and the National Cancer Institute of the National Institutes of Health (award no. R01CA163452)

\section{ABBREVIATIONS USED}

$\begin{array}{ll}\text { HDAC } & \text { histone deacetylase } \\ \text { HDACI } & \text { histone deacetylase inhibitor } \\ \text { SAHA } & \text { suberoylanilide hydroxamic acid } \\ \text { NO } & \text { nitrate oxide } \\ \text { EtOAc } & \text { acetic ether } \\ \text { TEA } & \text { triethylamine } \\ \text { PCC } & \text { pyridinium chlorochromate } \\ \text { DCM } & \text { dichloromethane } \\ \text { Py } & \text { pyridine }\end{array}$

\section{REFERENCES}

1. Muller S, Kramer HO. Inhibitors of HDACs-effective drugs against cancer. Curr. Cancer Drug Targets. 2010; 10:210-228. [PubMed: 20201785]

2. Venugopal B, Evans TRJ. Developing histone deactylase inhibitors as anti-cancer therapeutics. Curr. Med. Chem. 2011; 18:1658-1671. [PubMed: 21428881]

3. Marielle P, Marina P, Monica B, Daniela F. Histone deacetylase inhibitors: from bench to clinic. J. Med. Chem. 2008; 51:1505-1529. [PubMed: 18247554]

4. Bertrand P. Inside HDACwith HDAC inhibitors. Eur. J. Med. Chem. 2010; 45:2095-2116. [PubMed: 20223566]

5. Li Z, Zhu W-G. Targeting histone deacetylases for cancer therapy: from molecular mechanisms to clinical implications. Int. J. Biol. Sci. 2014; 7:757-770. [PubMed: 25013383]

6. Marks PA. Discovery and development of SAHA as an anticancer agent. Oncogene. 2007; 26:13511356. [PubMed: 17322921]

7. Marks PA, Breslow R. Dimethyl sulfoxide to vorinostat: development of this histone deacetylase inhibitor as an anticancer drug. Nat. Biotechnol. 2007; 25:84-90. [PubMed: 17211407] 
8. Varasi M, Thaler F, Abate A, Boggio C, Boggio R, Carenzi G, Cataudella T, Zuffo RD, Fulco MC, Rozio MG, Mai A, Dondio G, Minucci S, Mercurio C. Discovery synthesis pharmacological evaluation of spiropiperidine hydroxamic acid based derivatives as structurally novel histone deacetylase (HDAC) inhibitors. J. Med. Chem. 2011; 54:3051-3064. [PubMed: 21417419]

9. Furchgott RF, Zawadzki J. V The obligatory role of endothelial cells in the relaxation of arterial smooth muscle by acetylcholine. Nature. 1980; 288:373-376. [PubMed: 6253831]

10. Scatena R, Bottoni P, Martorana GE, et al. Nitric oxide donor drugs: an update on pathophysiology threapreutically potential. Expert. Opin. Invest. Drugs. 2005; 14:835-846.

11. Megson IL. Nitric oxide donor drugs. Drugs Future. 2000; 25:701-705.

12. Nathan CF, Hibbs JB Jr. Role of nitric oxide synthesis in macrophage antimicrobial activity. Curr. Opin. Immunol. 1991; 3:65-70. [PubMed: 1711326]

13. Stuehr DJ, Nathan CF. Nitric oxide. A macrophage product responsible for cytostasis and respiratory inhibition in tumor target cells. J. Exp. Med. 1989; 169:1543-1555. [PubMed: 2497225]

14. Bonfoco E, Krainc D, Ankarcrona M. Apoptosis and necrosis: two distinct events induced respectively, by mild intense insults with $\mathrm{N}$-methyl-D-aspartate or nitric oxide/superoxide in cortical cell cultures. Proc. Natl. Acad. Sci. U.S.A. 1995; 92:7162-7166. [PubMed: 7638161]

15. Konovalova NP, Goncharova SA, Volkova LM, et al. Nitric oxide donor increase the efficiency of cytostatic therapy and retards the development of drug resistance. Nitric Oxide. 2003; 8:59-64. [PubMed: 12586543]

16. Wang PG, Xian M, Tang XP, et al. Nitric oxide donors: chemical activities biological applications. Chem. Rev. 2002; 102:1091-1134. [PubMed: 11942788]

17. Dhar A, Brindley JM, Stark C, Citro ML, Keefer LK, Colburn NH. Nitric oxide does not mediate but inhibits transformation and tumor phenotype. Mol. Cancer Ther. 2003; 2:1285-1293. [PubMed: 14707269]

18. Maksimovic-Ivanic D, Mijatovic S, Harhaji L, Miljkovic D, Dabideen D, Fan Cheng K, Mangano K, Malaponte G, Al-Abed Y, Libra M, Garotta G, Nicoletti F, Stosic-Grujicic S. Anticancer properties of the novel nitric oxide-donating compound ( $S, R)$-3-phenyl-4 5-dihydro-5-isoxazole acetic acid-nitric oxide in vitro, in vivo. Mol. Cancer Ther. 2008; 7:510-520. [PubMed: 18347138]

19. Feelisch M, Schonafinger K, Noack E. Thiol-mediated Generation of nitric oxide accounts for the vasodilator action of phenylsulfonylfuroxansBiochem. Pharmacol. 1992; 44:1149-1157.

20. Chen L, Zhang Y, Kong X, Lan E, Huang Z, Peng S, Kaufman DL, Tian J. Design, synthesis, and antihepatocellular carcinoma activity of nitric oxide releasing derivatives of oleanolic acid. J. Med. Chem. 2008; 51:4834-4838. [PubMed: 18598019]

21. Ling Y, Ye XL, Ji H, Zhang YH, Lai YSh, Peng SX, Tian JD. Synthesis and evaluation of nitric oxide-releasing derivatives of farnesylthiosalicylic acid as anti-tumor agents. Bioorg. Med. Chem. 2010; 18:3448-3456. [PubMed: 20435479]

22. Moharram S, Zhou A, Wiebe LI, Knaus EE. Design and synthesis of 3'-5'-O-(3benzenesulfonylphenylsulfonylfuroxan-4-yl)-2'-deoxyuridines: biological evaluation as hybrid nitric oxide donor-nucleoside anticancer agents. J. Med. Chem. 2004; 47:1840-1846. [PubMed: 15027876]

23. Han C, Huang ZJ, Zheng C, Wan LD, Zhang LW, Peng SX, Ding K, Ji HB, Tian JD, Zhang YH. Novel hybrids of phenylsulfonylfuroxan and anilinopyrimidine as potent selective epidermal growth factor receptor inhibitors for intervention of non-small-cell lung cancer. J. Med. Chem. 2013; 56:4738-4748. [PubMed: 23668441]

24. Illi B, Dello Russo C, Colussi C, Rosati J, Pallaoro M, Spallotta F, Rotili D, Valente S, Ragone G, Martelli F, Biglioli P, Steinkuhler C, Gallinari P, Mai A, Capogrossi MC, Gaetano C. Nitric oxide modulates chromatin folding in human endothelial cells via protein phosphatase $2 \mathrm{~A}$ activation and class IIhistone deacetylases nuclear shuttling. Circ. Res. 2008; 102:51-58. [PubMed: 17975112]

25. Colussi C, Mozzetta C, Gurtner A, Illi B, Rosati J, Straino S, Ragone G, Pescatori M, Zaccagnini G, Antonini A, Minetti G, Martelli F, Piaggio G, Gallinari P, Steinkulher C, Clementi E, Dell”" Aversana C, Altucci L, Mai A, Capogrossi MC, Puri PL, Gaetano C. HDAC2 blockade by nitric oxide and histone deacetylase inhibitors reveals a common target in duchenne muscular dystrophy treatment. Proc. Natl. Acad. Sci. U.S.A. 2008; 105:19183-19187. [PubMed: 19047631] 
26. Feng JH, Jing FB, Fang H, Gu LC, Xu WF. Expression purification S-nitrosylation of recombinant histone deacetylase 8 in Escherichia coli . BioSci. Trends. 2011; 5:17-22. [PubMed: 21422596]

27. Nott A, Watson PM, Robinson JD, Crepaldi L, Riccio A. S-Nitrosylation of histone deacetylase 2 induces chromatin remodeling in neurons. Nature. 2008; 455:411-415. [PubMed: 18754010]

28. Spallotta F, Cencioni C, Straino S, Nanni S, Rosati J, Artuso S, Manni I, Colussi C, Piaggio G, Martelli F, Valente S, Mai A, Capogrossi MC, Farsetti A, Gaetano CA. nitric oxide-dependent cross-talk between class I and III histone deacetylases accelerates skin repair. J. Biol. Chem. 2013; 288:11004-11012. [PubMed: 23463510]

29. Kee HJ, Kook H. Roles and targets of class I and IIa histone deacetylases in cardiac hypertrophy. J. Biomed. Biotechnol. 2011:928326. [PubMed: 21151616]

30. Isenberg JS, Ridnour LA, Espey MG, Wink DA, Roberts DD. Nitric oxide in wound-healing. Microsurgery. 2005; 25:442-451. [PubMed: 16044466]

31. Soneja A, Drews M, Malinski T. Role of nitric oxide, nitroxidative and oxidative stress in wound healing. Pharmacol. Rep. 2005; 57:108-119. [PubMed: 16415491]

32. Zhang YJ, Fang H, Feng JH, Jia YP, Wang XJ, Xu WF. Discovery of a tetrahydroisoquinolinebased hydroxamic acid derivative (ZYJ-34c) as histone deacetylase inhibitor with potent oral antitumor activities. J. Med. Chem. 2011; 54:5532-5539. [PubMed: 21714538]

33. Ling Y, Ye XL, Zhang Z, Zhang YH, Lai Y, Ji H, Peng SX, Tian JD. Novel nitric oxide-releasing derivatives of farnesylthiosalicylic acid: synthesis evaluation of antihepatocellular carcinoma activity. J. Med. Chem. 2011; 54:3251-3259. [PubMed: 21504204]

34. Borretto E, Lazzarato L, Spallotta F, Cencioni C, D'Alessandra Y, Gaetano C, Fruttero R, Gasco A. Synthesis biological evaluation of the first example of NO donor histone deacetylase inhibitor. ACS Med. Chem. Lett. 2013; 4:994-999. [PubMed: 24900596] 


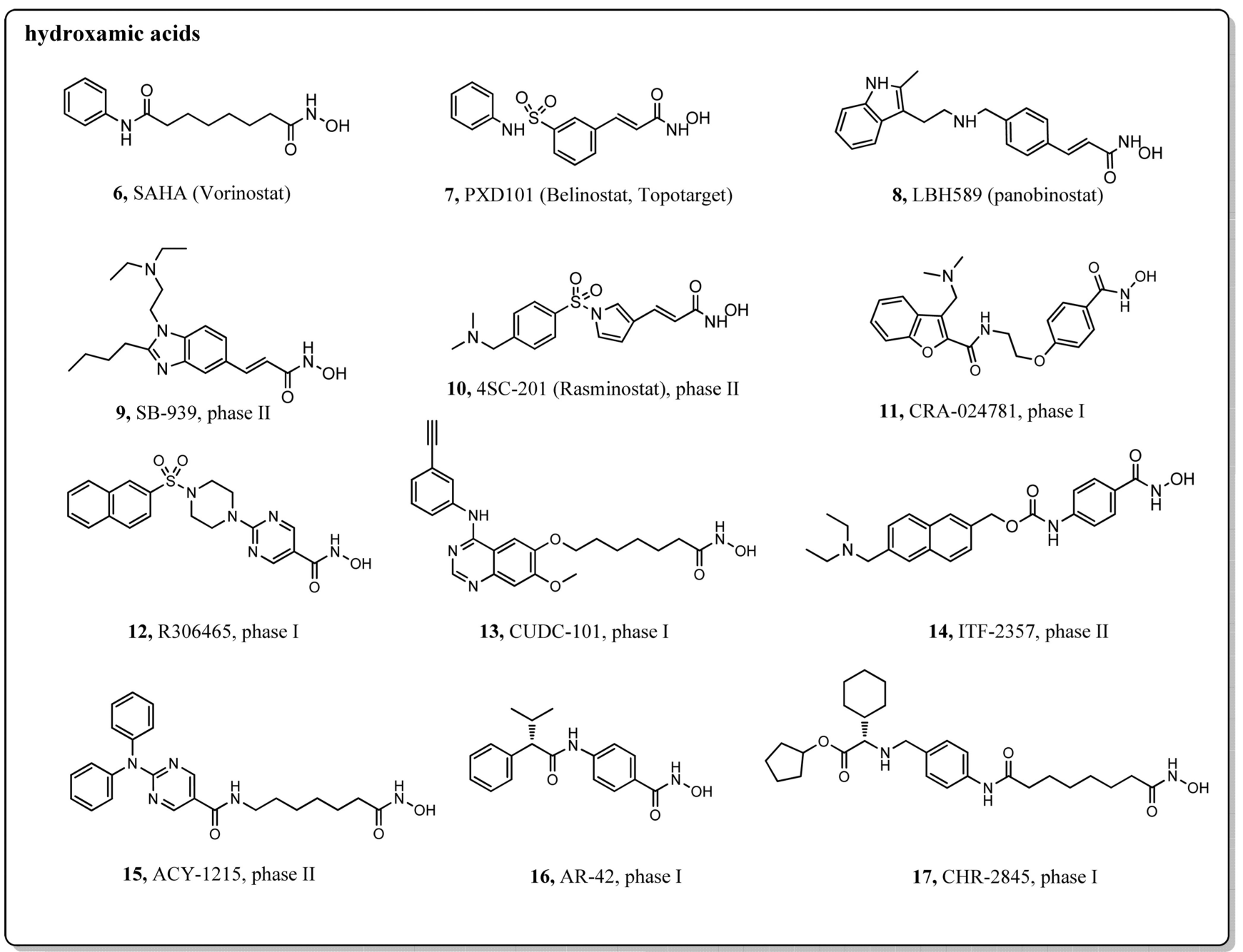

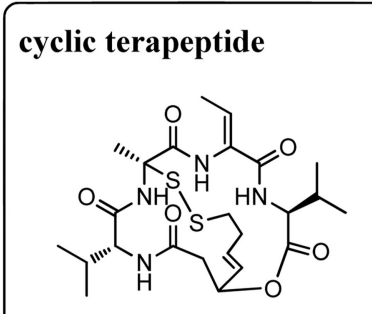

18, FK228(Romidepsin) short-chain fatty acid

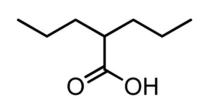

19, Valproic benzamides

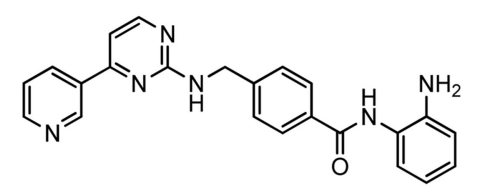

20, MGCD-0103 (Methylgene)

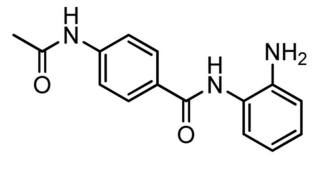

21, CI-994 (Tacedinaline)

Figure 1.

Pharmacophore model and structures of representative HDAC inhibitors. 

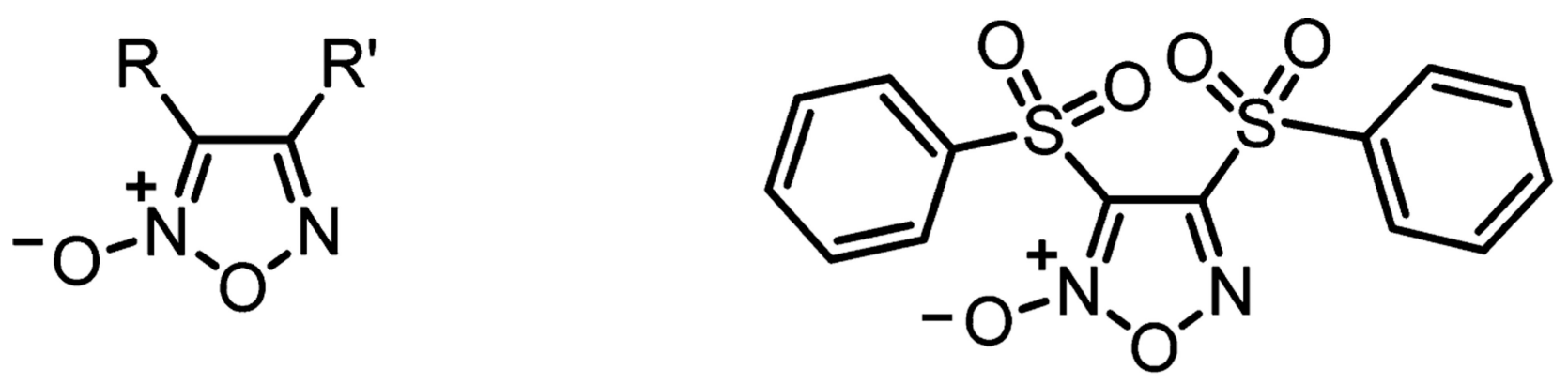

\section{2, Oxadiazole}

\section{3, phenylsulfonylfuroxan}

Figure 2.

Chemical structures of oxadiazole and phenylsulfonylfuroxan. 
<smiles>Nc1ccccc1NC(=O)c1ccc(CNC(=O)OCc2cccnc2)cc1</smiles>

24, MS275<smiles>CO[N+]1ON=C(CN(C)Cc2ccc(COC(=O)NCc3ccc(C(=O)Nc4ccccc4N)cc3)cn2)C1C#N</smiles>

25, NO-MS275

Figure 3.

Chemical structures of MS275 and NO-MS275. 


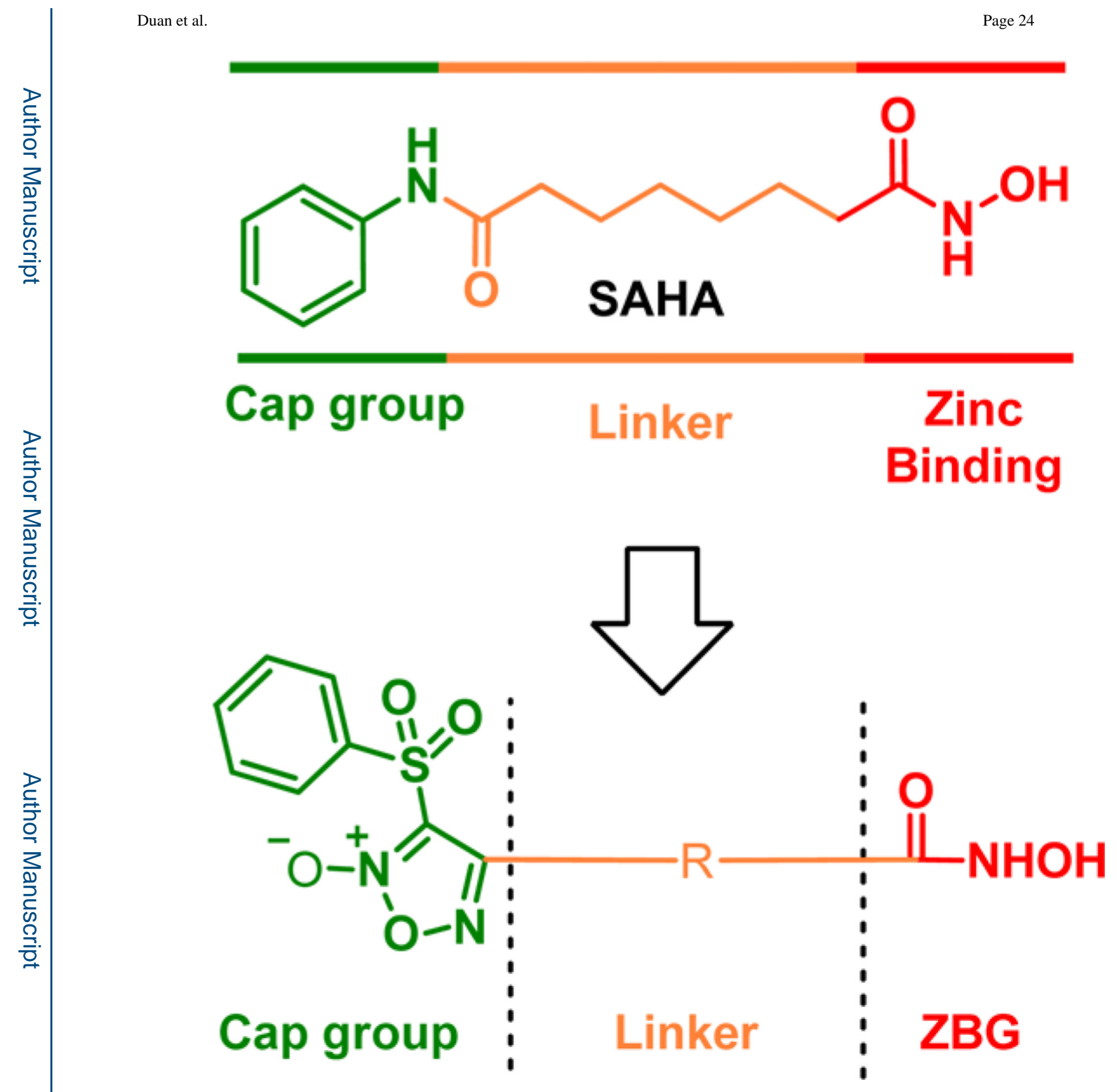

Figure 4.

Design strategy of the target compounds. 


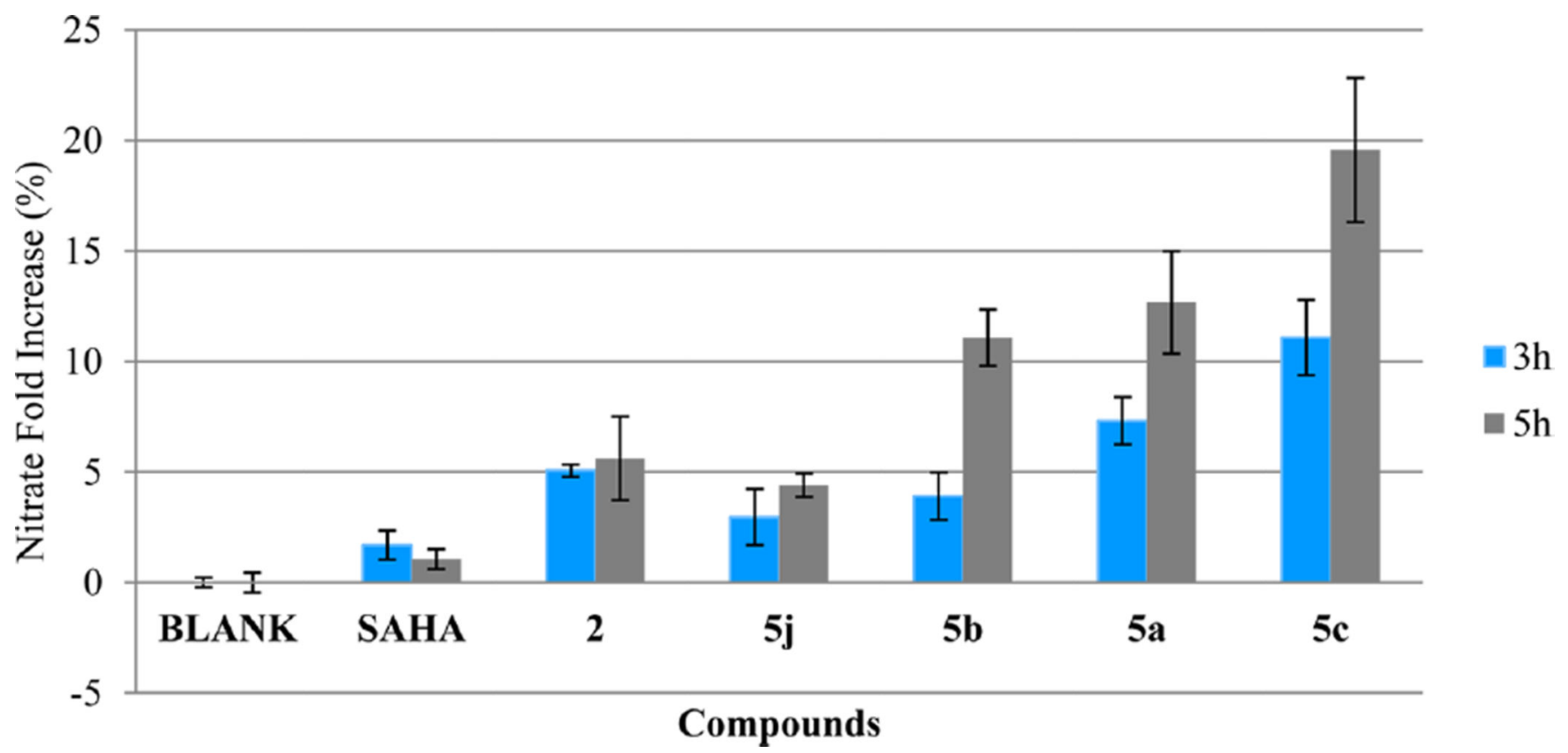

Figure 5.

NO production by the indicated compounds and SAHA in HEL cells. Data are the mean value \pm SD obtained from three independent experiments. 


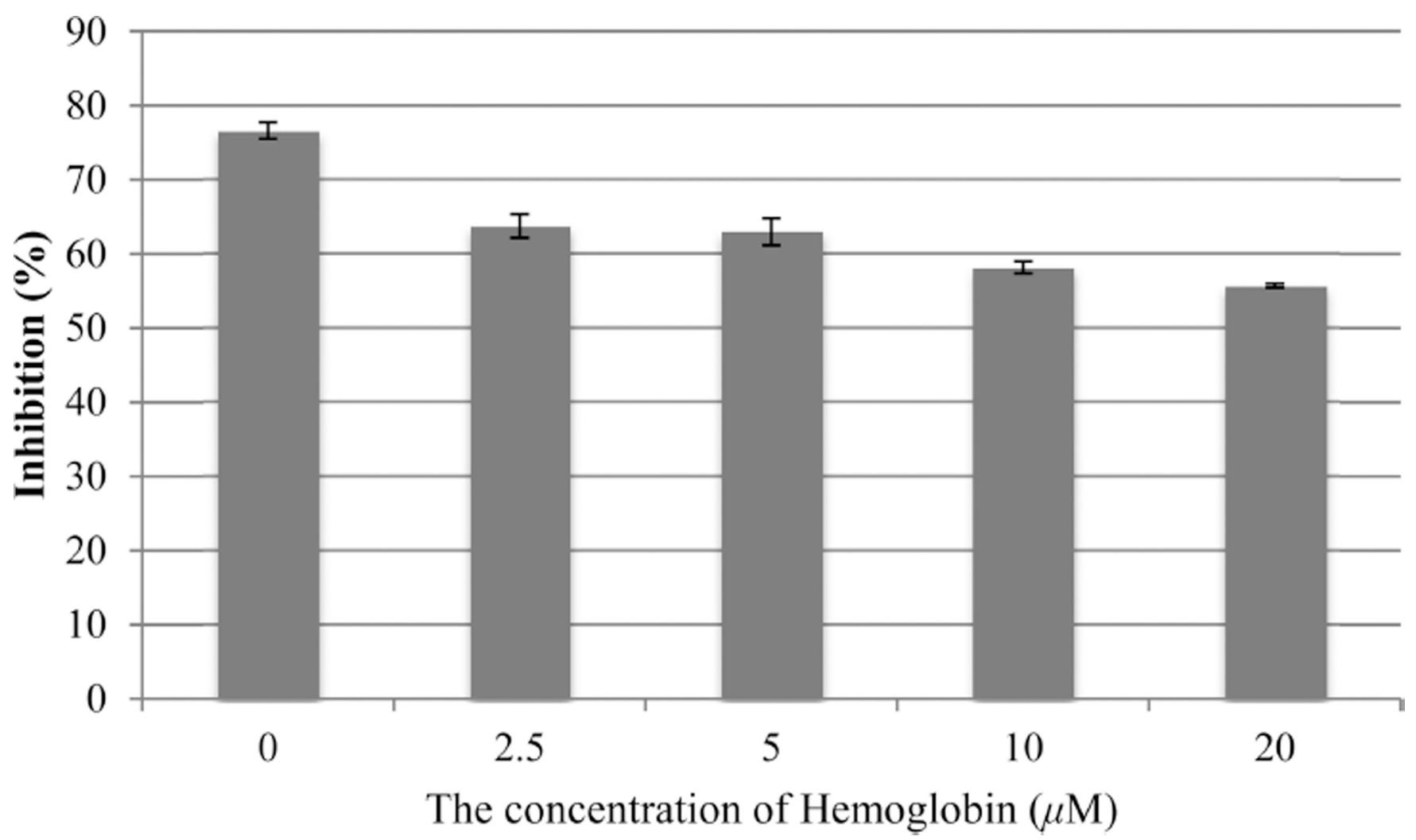

Figure 6.

Effects of hemoglobin on the antiproliferative activity of $\mathbf{5 c}$ in HEL cells. Data are the mean value \pm SD obtained from three independent experiments. 
A

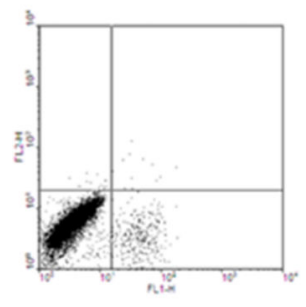

SAHA

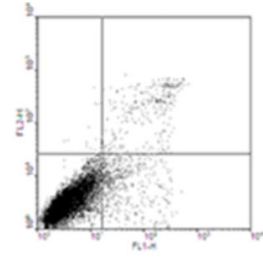

$0.5 \mu \mathrm{mol} / \mathrm{L}$

DMSO
2

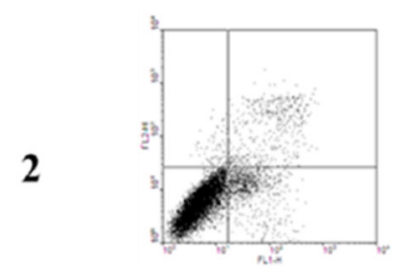

$0.5 \mu \mathrm{mol} / \mathrm{L}$

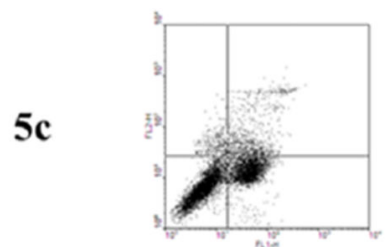

$0.5 \mu \mathrm{mol} / \mathrm{L}$

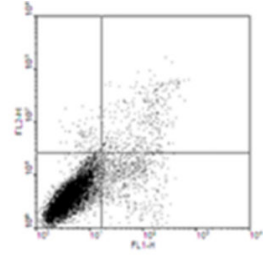

$1 \mu \mathrm{mol} / \mathrm{L}$

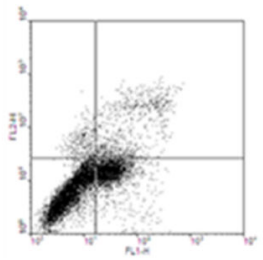

$1 \mu \mathrm{mol} / \mathrm{L}$

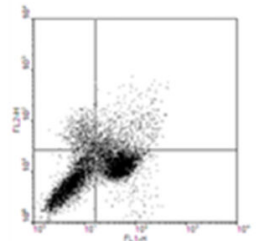

$1 \mu \mathrm{mol} / \mathrm{L}$

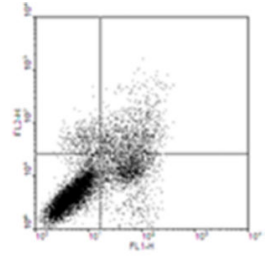

$2 \mu \mathrm{mol} / \mathrm{L}$

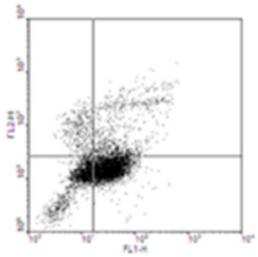

$2 \mu \mathrm{mol} / \mathrm{L}$

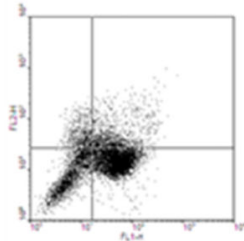

$2 \mu \mathrm{mol} / \mathrm{L}$

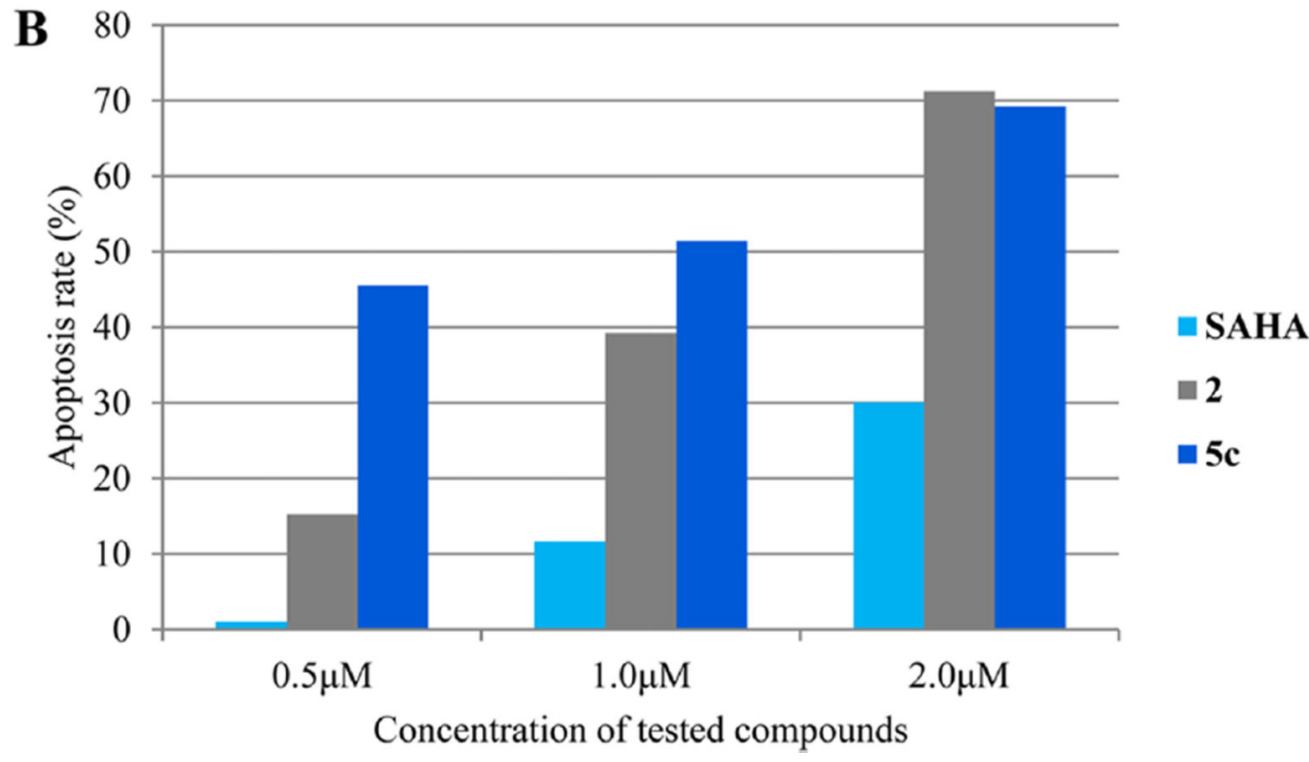

Figure 7.

Apoptotic index analysis of SAHA, $\mathbf{2}$, and $\mathbf{5 c}$ at different concentrations in HEL cells: (A) flow cytometry analysis and (B) bar chart of therate of apoptosis. 

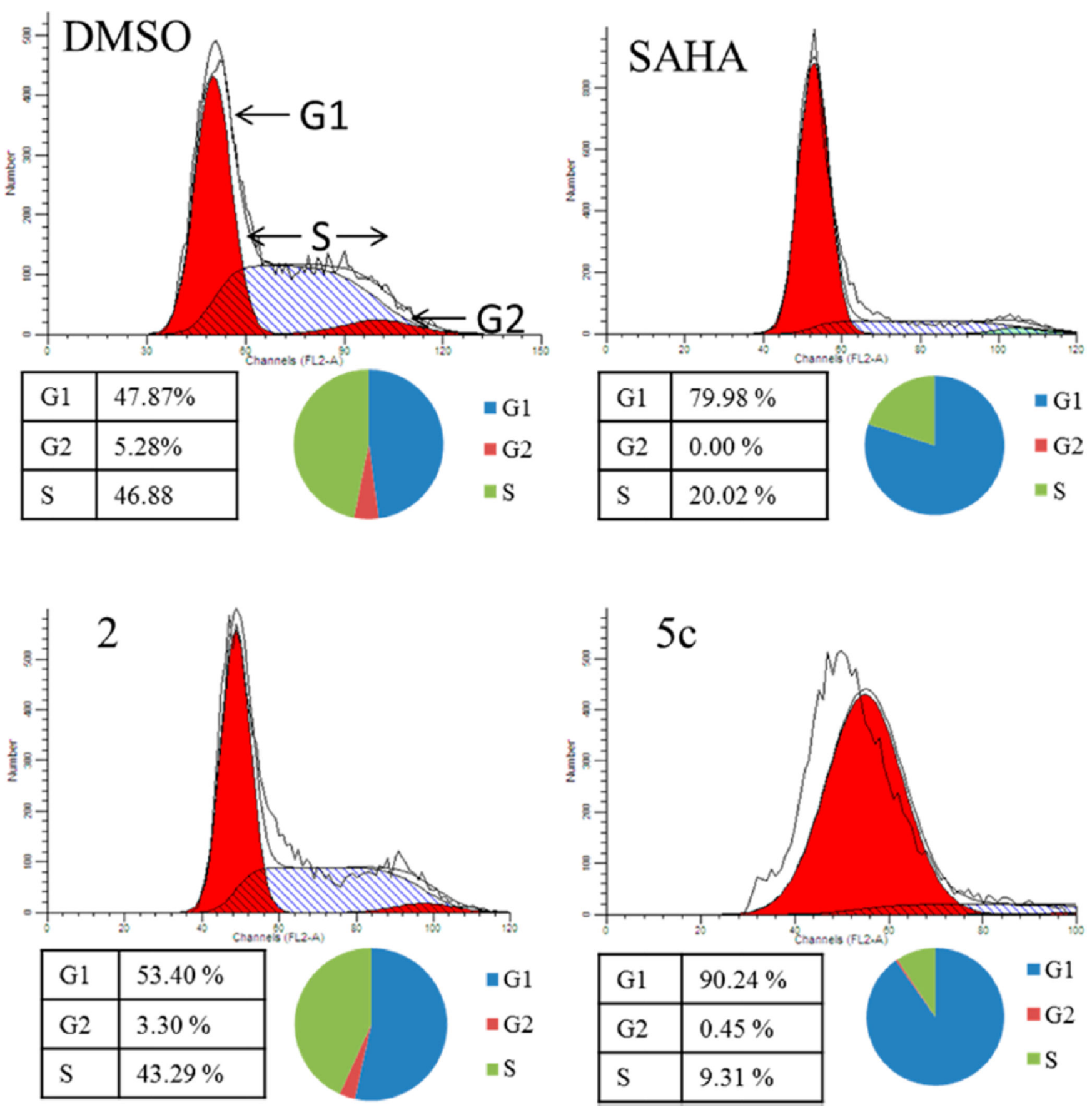

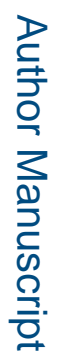

Figure 8.

Effect of SAHA, 2, and 5c in HEL cell cycle progression. 


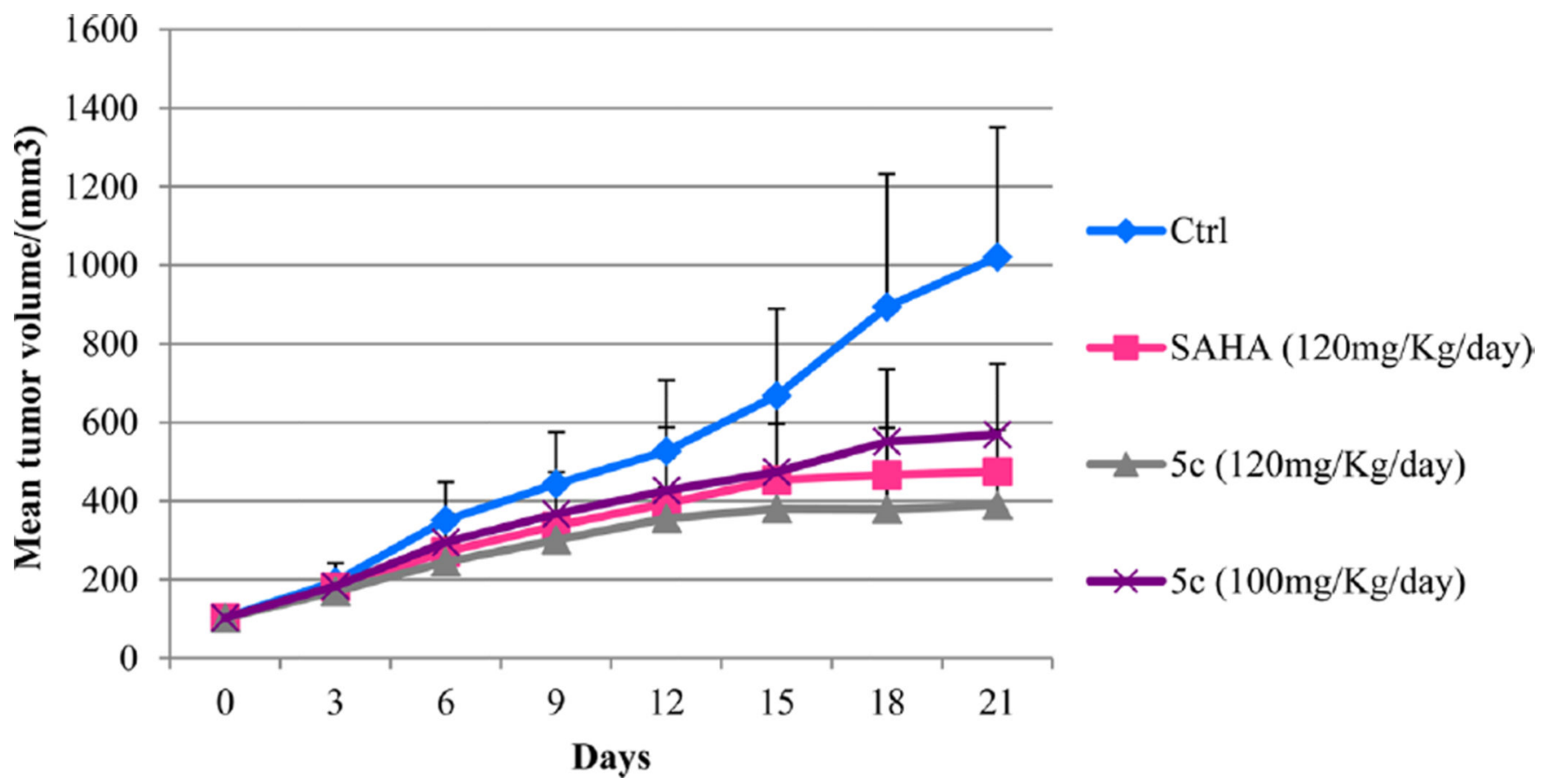

Figure 9.

Growth curve of implanted HEL xenografts in nude mice. Data are expressed as the mean \pm SD. 


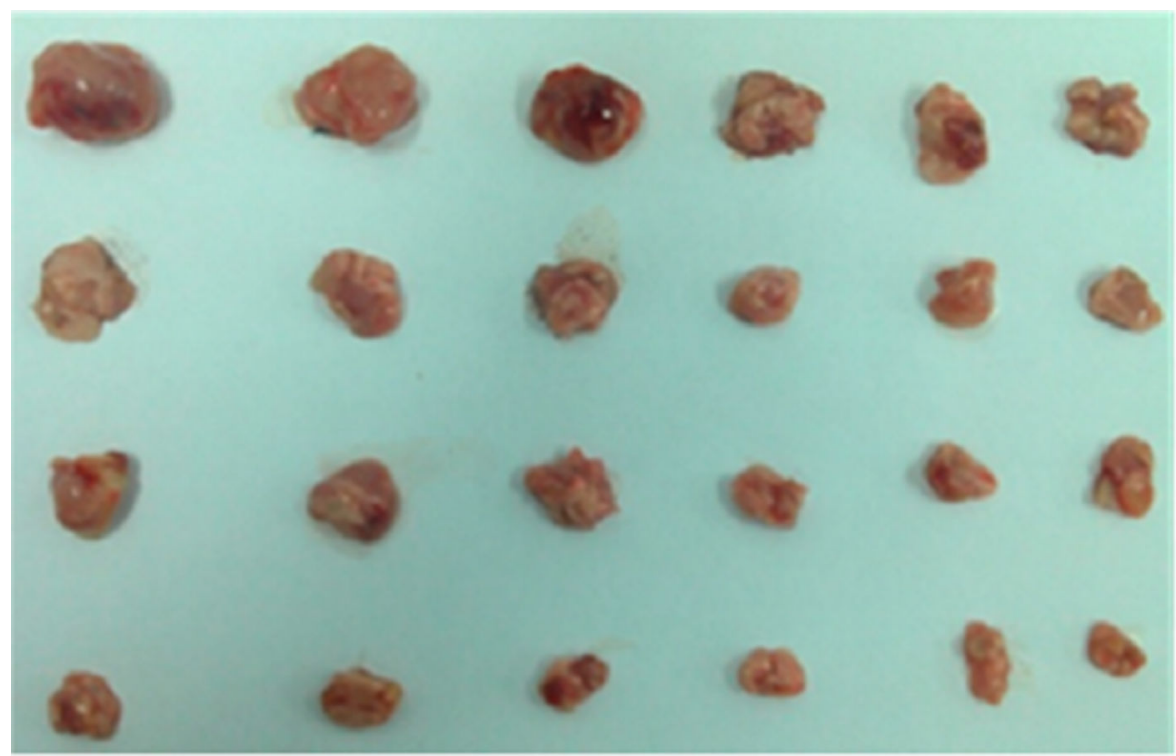

Ctrl

SAHA (120mg/Kg/day)

Figure 10.

5c $(100 \mathrm{mg} / \mathrm{Kg} /$ day $)$

Photograph of dissected HEL tumor tissues. 


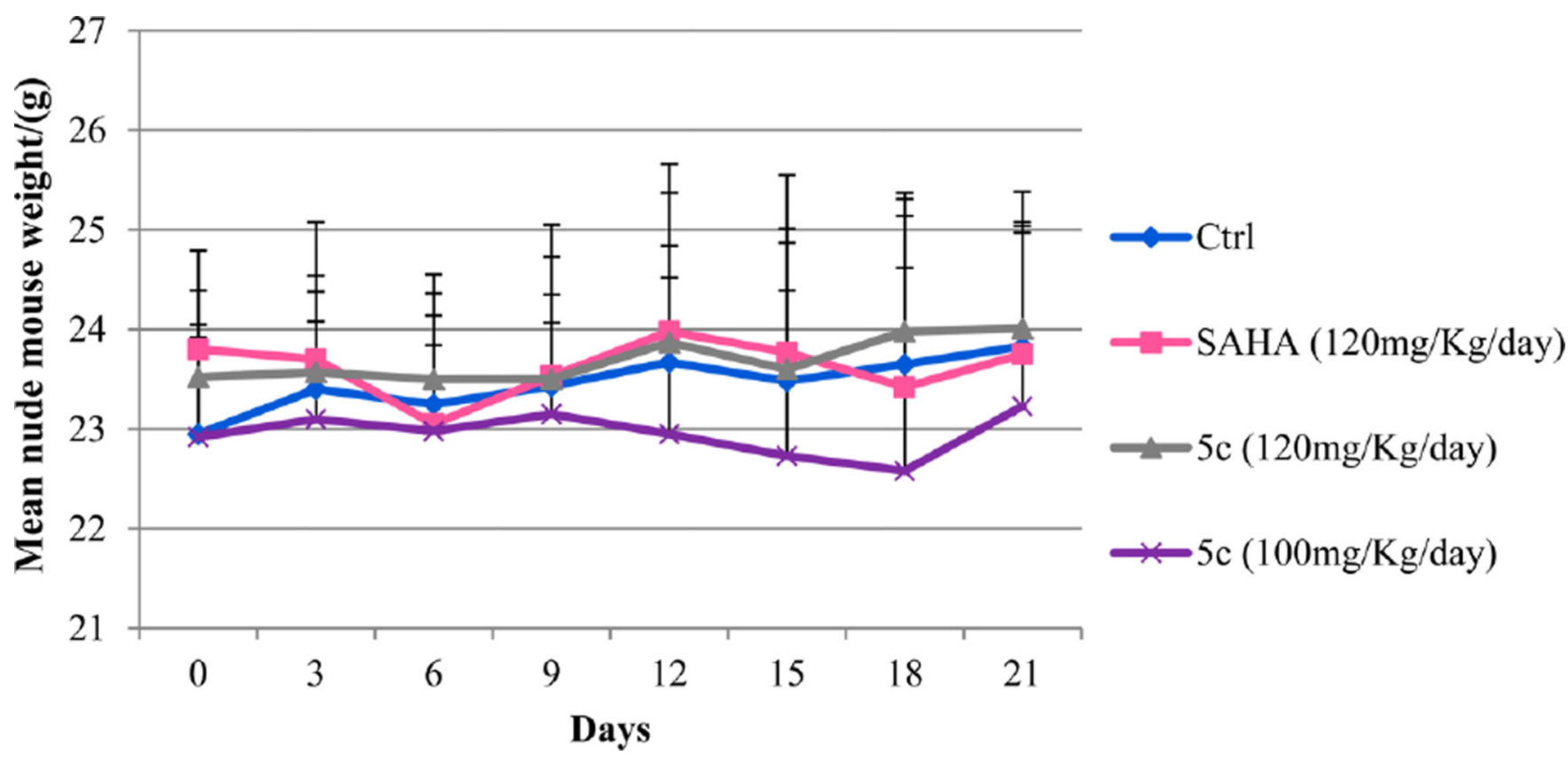

Figure 11.

Growth curve of nude mouse weight. Data are expressed as the mean \pm SD. 

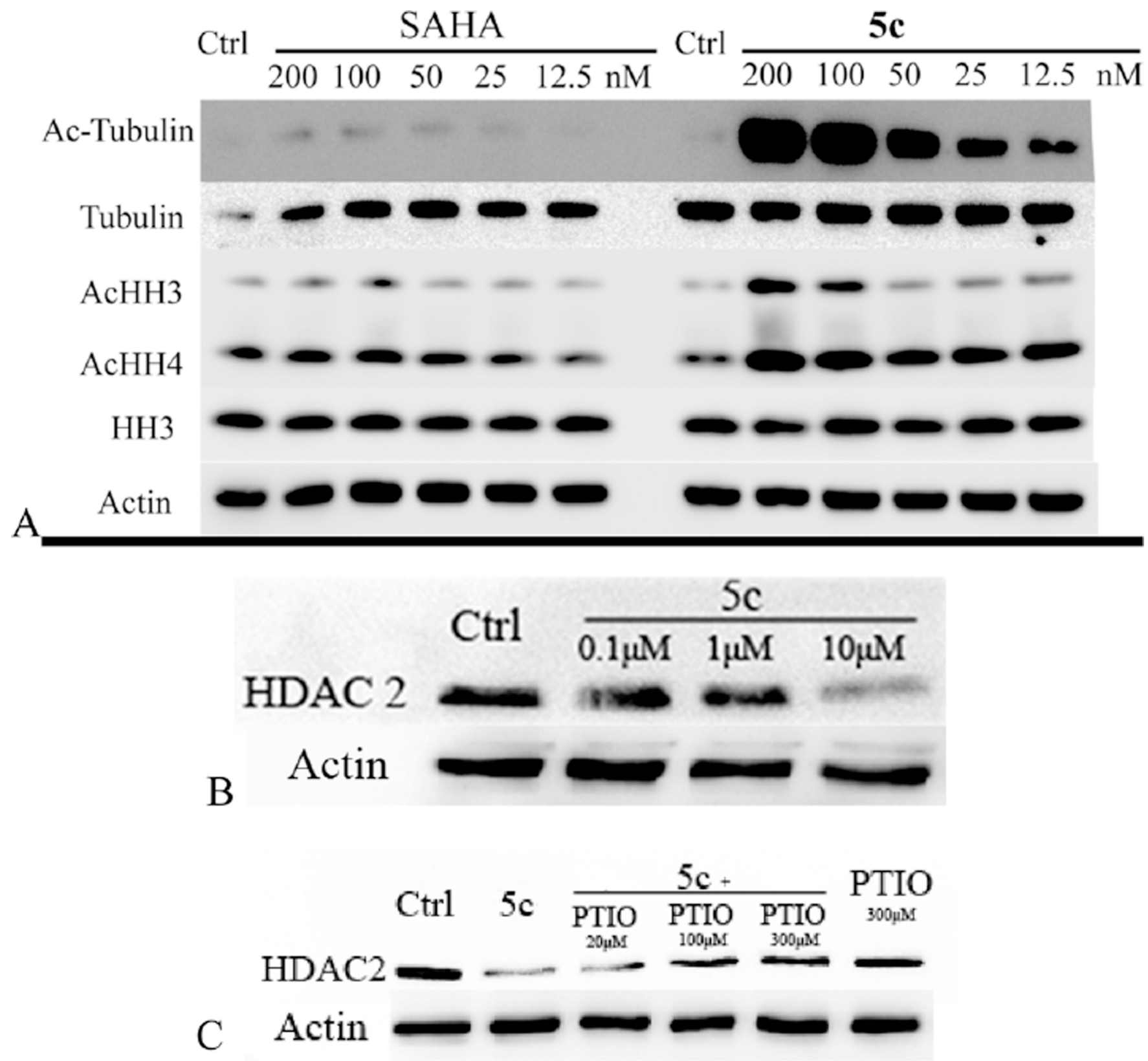

Figure 12.

(A)Western blot analysis of acetylated tubulin, tubulin, acetylated histone $\mathrm{H} 3$, acetylated histone $\mathrm{H} 4$, and histone $\mathrm{H} 3$ after 3 h treatment with $12.5,25,50,100$, or $200 \mathrm{nM} 5 \mathrm{c}$ in MV4-11 AML cells. (B) Western blot analysis of HDAC 2 after $3 \mathrm{~h}$ treatment with 0.1 , 1, or $10 \mu \mathrm{M} 5 \mathrm{c}$ in HEL cells. (C) Western blot analysis of HDAC 2 after $5 \mathrm{~h}$ treatment with 10 $\mu \mathrm{M} 5 \mathrm{c}$ and 20,100 , or $300 \mu \mathrm{M}$ PTIO in HEL cells. 


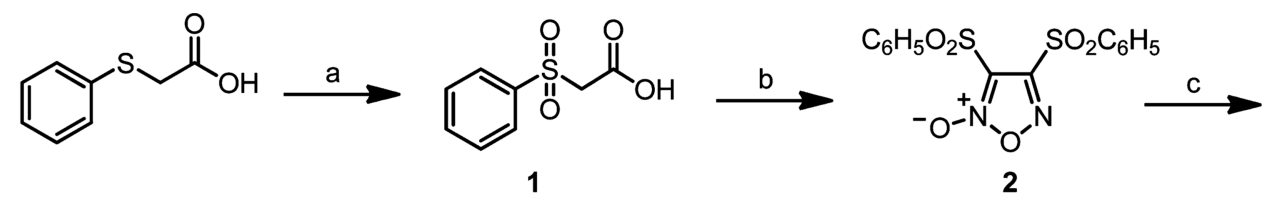<smiles>CC(C)[C@H](OC(=O)O)c1nonc1S(=O)(=O)c1ccccc1</smiles><smiles></smiles>

3a, 4a, 5a: $\mathrm{R}=\left(\mathrm{CH}_{2}\right)_{3}$ $3 b, 4 b, 5 b: R=\left(\mathrm{CH}_{2}\right)_{4}$ 3c, $4 \mathrm{c}, 5 \mathrm{c}: \mathrm{R}=\left(\mathrm{CH}_{2}\right)_{5}$ 3d, 4d, 5d: $\mathrm{R}=\left(\mathrm{CH}_{2}\right)_{6}$ $3 e, 4 e, 5 e: R=\left(\mathrm{CH}_{2}\right)_{7}$ 3f, 4f, 5f: $\mathrm{R}=\left(\mathrm{CH}_{2}\right)_{2} \mathrm{O} \mathrm{CH}$ $3 \mathrm{~g}, 4 \mathrm{~g}, 5 \mathrm{~g}: \mathrm{R}=\mathrm{CH}_{2} \mathrm{C}\left(\mathrm{CH}_{3}\right)_{2}$ 3h, 4h, 5h: $\mathrm{R}=\mathrm{CH}_{2} \mathrm{CHCH}$ 3i, 4i, 5i: $\mathrm{R}=\left(\mathrm{CH}_{2} \mathrm{CH}_{2} \mathrm{O}\right)_{2} \mathrm{CH}_{2}$

3j, 4j, 5j: R=p-Ph

3k, 4k, 5k: R=m-Ph

3l, 4l, 5l: R=p-2-( $\left.\mathrm{CH}_{3} \mathrm{O}\right)-\mathrm{Ph}$

$3 \mathrm{~m}, 4 \mathrm{~m}, 5 \mathrm{~m}: \mathrm{R}=\mathrm{p}-\mathrm{Ph}-\mathrm{CH}_{2}$

3n, 4n, 5n: $\mathrm{R}=\mathrm{CH}_{2} \mathrm{C}\left(\mathrm{CH}_{3}\right)\left(\mathrm{CH}_{2} \mathrm{CH}_{2} \mathrm{CH}_{3}\right)$

Scheme 1.

Synthesis of Compounds 5a-5oa

${ }^{a}$ Reagents and conditions: (a) $\mathrm{H}_{2} \mathrm{O}_{2}, \mathrm{CH}_{3} \mathrm{COOH}$; (b) conc. $\mathrm{HNO}_{3}$; (c) linker with two hydroxyl groups, $25 \% \mathrm{NaOH}$; (d) Jones reagent, acetone; (e) isobutyl chlorocarbonate, TEA, THF; $\mathrm{NH}_{2} \mathrm{OH} \cdot \mathrm{HCl}, \mathrm{CH}_{3} \mathrm{OH}$; (f) PCC, DCM, $0{ }^{\circ} \mathrm{C}$; (g) propandioic acid, pyrrolidine, Py, reflux. 


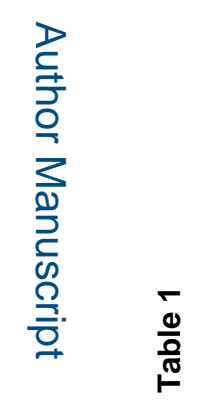

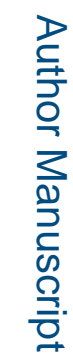

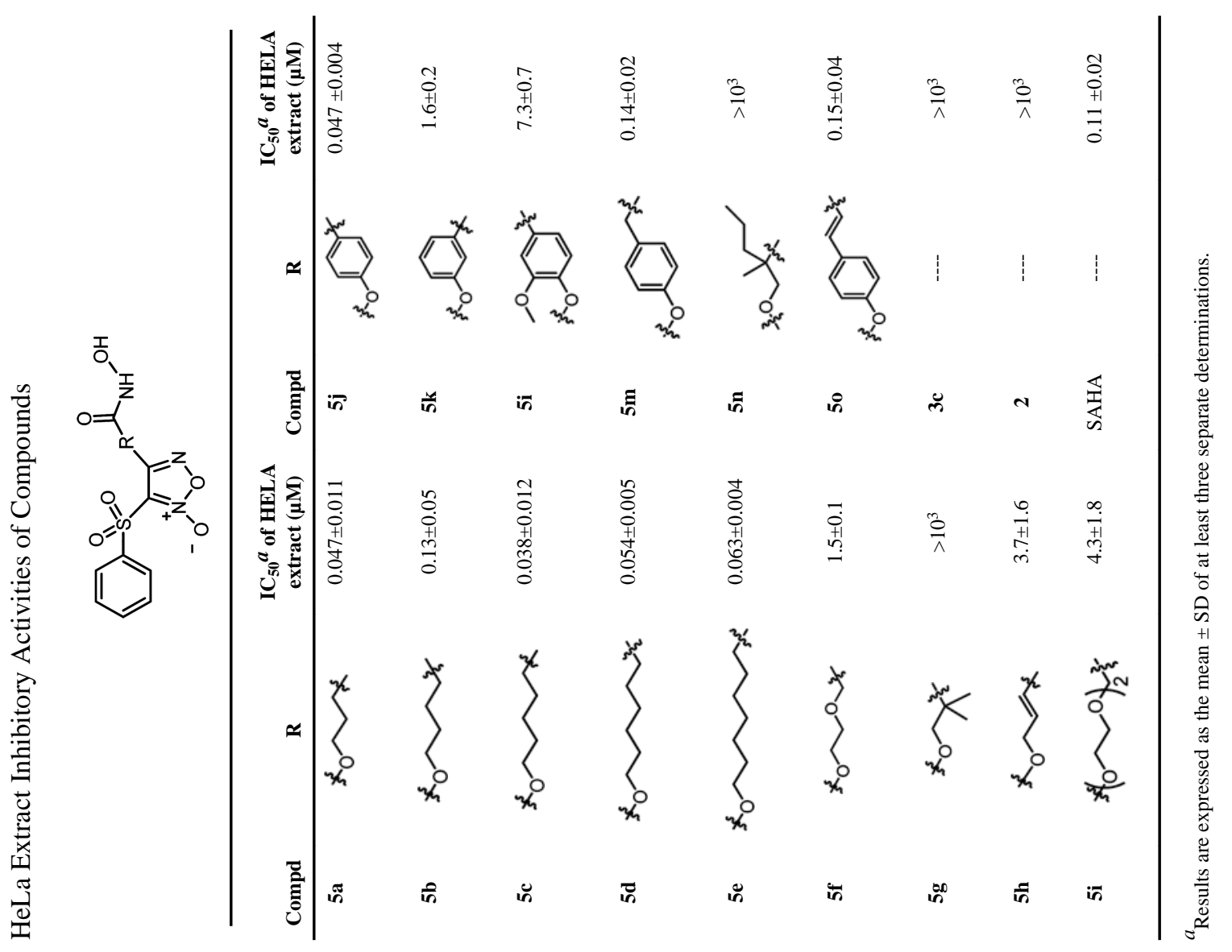

J Med Chem. Author manuscript; available in PMC 2016 May 28. 


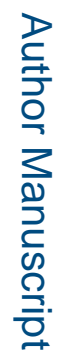

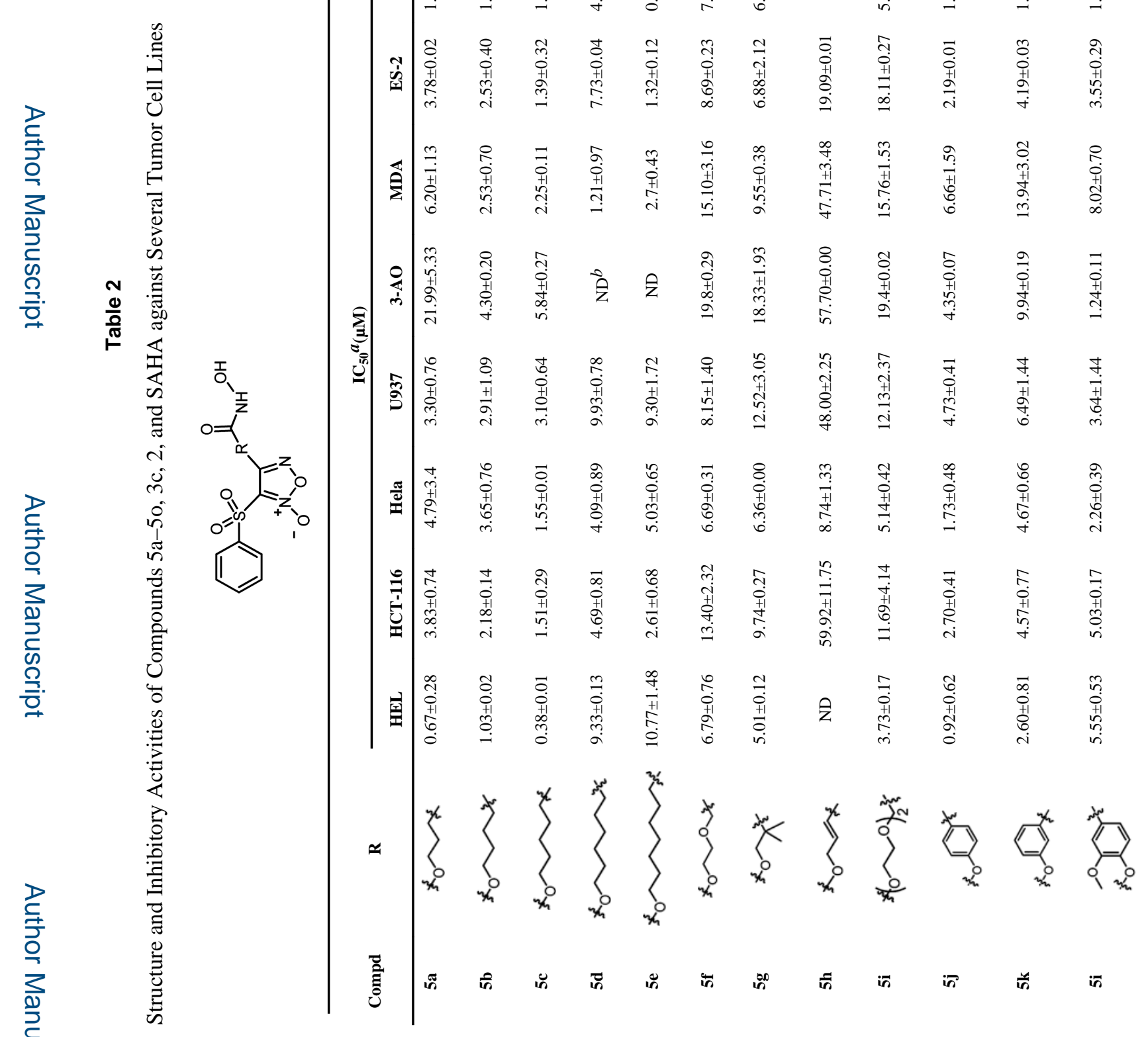

J Med Chem. Author manuscript; available in PMC 2016 May 28. 


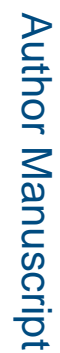

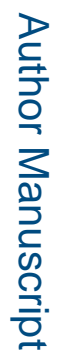

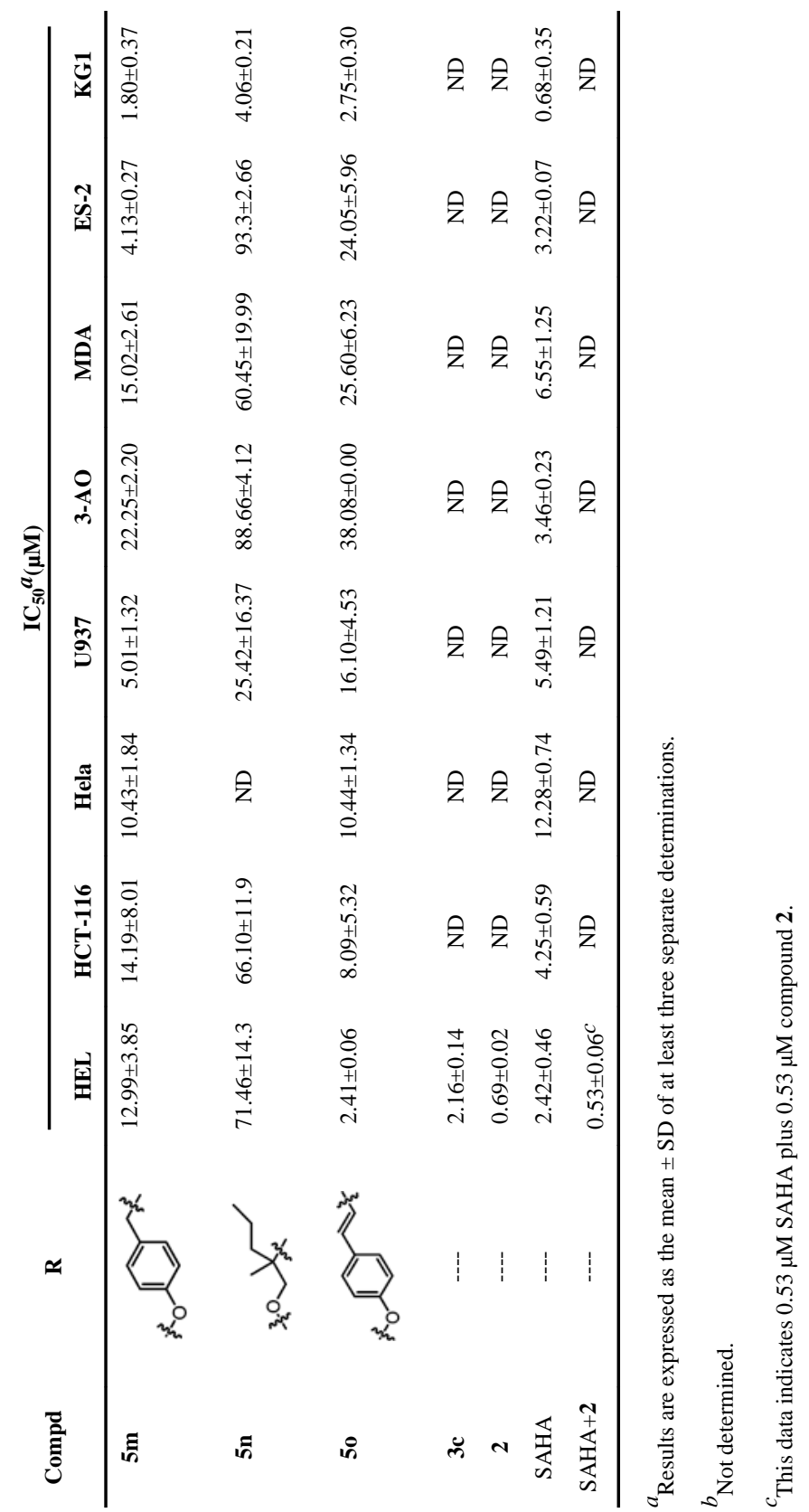

를

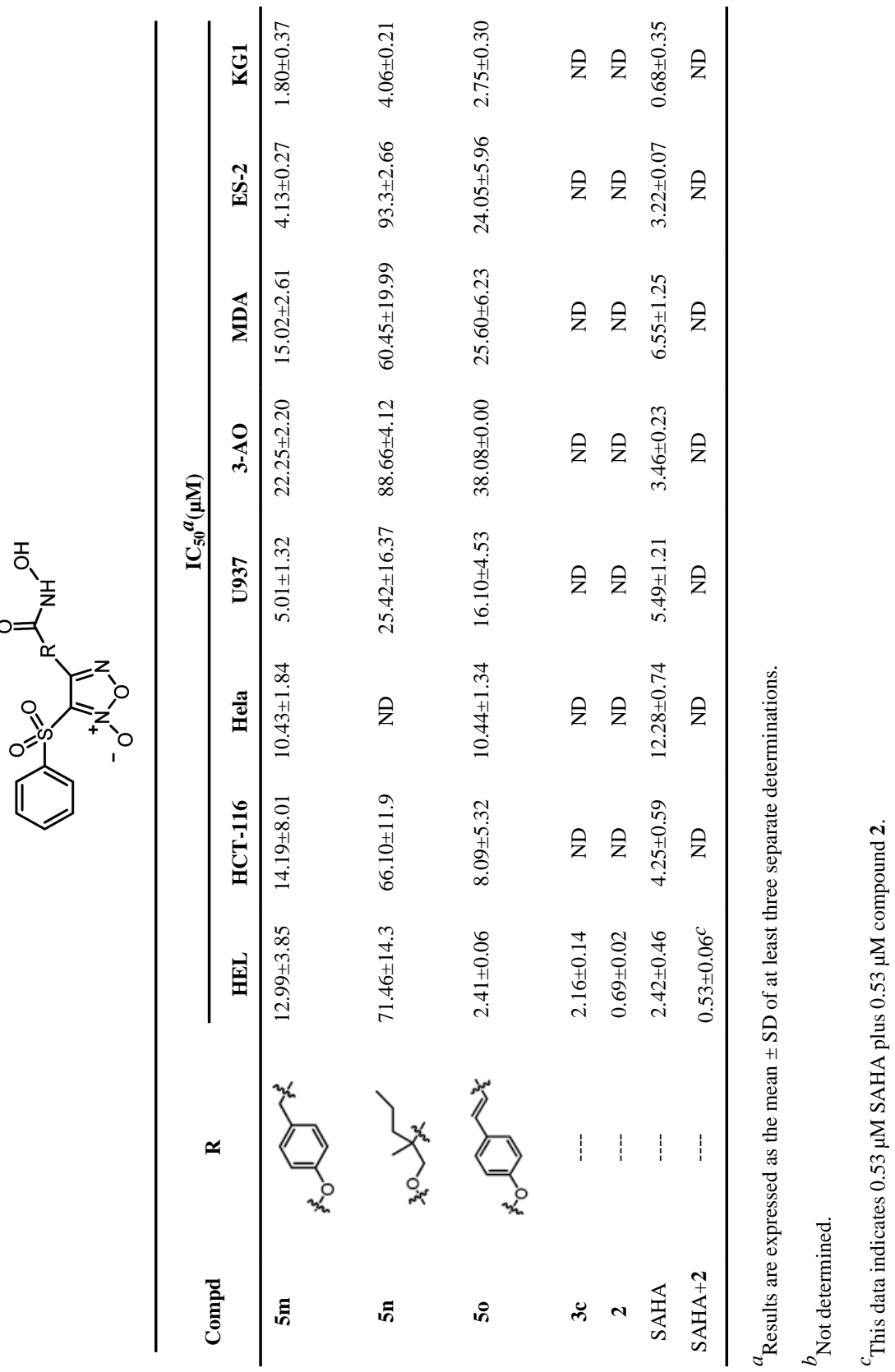

J Med Chem. Author manuscript; available in PMC 2016 May 28. 


\section{Table 3}

In Vivo Antitumor Activity in the HEL Xenograft $\mathrm{Model}^{a}$

\begin{tabular}{lcc}
\hline compd & TGI $(\boldsymbol{\%})$ & T/C (\%) \\
\hline SAHA (120 mg/kg/day) & 39 & 46 \\
$\mathbf{5 c}(120 \mathrm{mg} / \mathrm{kg} /$ day $)$ & 48 & 39 \\
$\mathbf{5 c}(100 \mathrm{mg} / \mathrm{kg} /$ day $)$ & 38 & 56 \\
\hline
\end{tabular}

${ }^{a}$ Compared with the control group, all treated groups showed statistically significant $(p<0.05) T / C$ and TGI by Student's two-tailed $t$ test. 


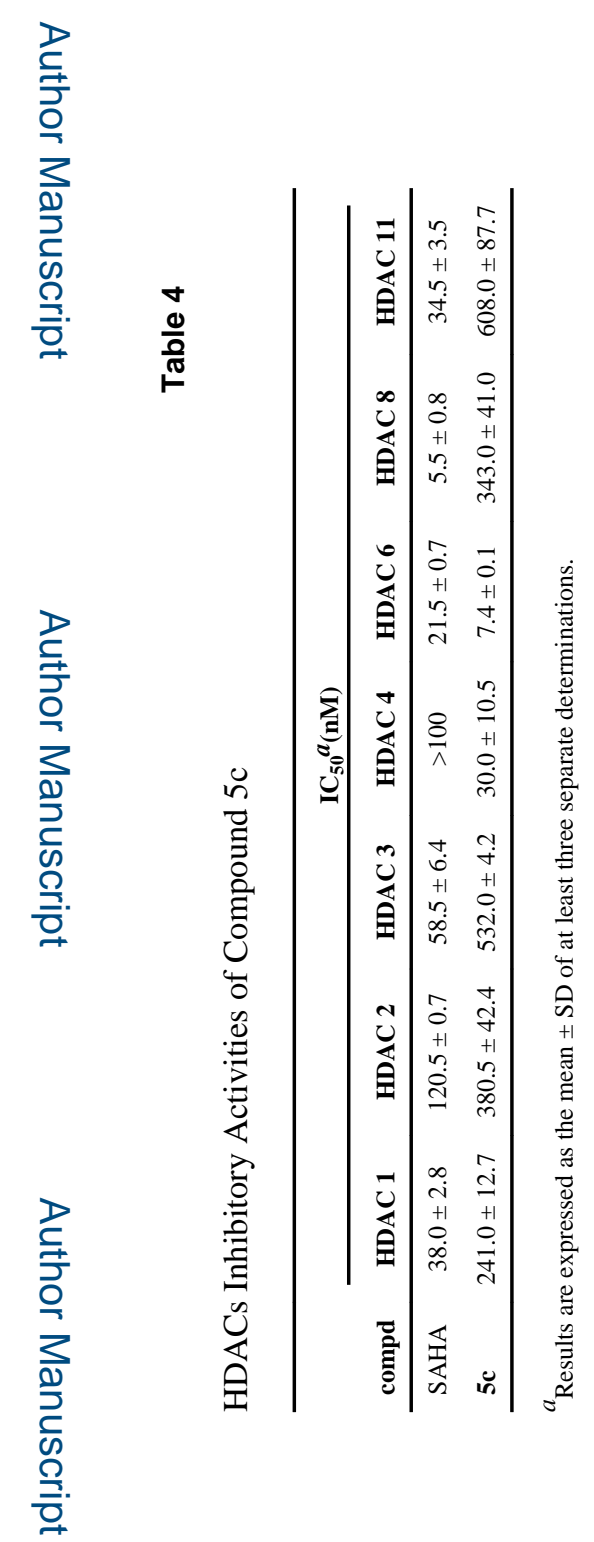

J Med Chem. Author manuscript; available in PMC 2016 May 28. 